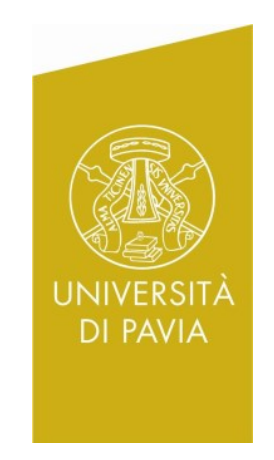

Department of Economics and Management DEM Working Paper Series

\title{
Price Discrimination in the Italian Medical Device Industry: An Empirical Analysis
}

\author{
Alberto Cavaliere \\ (Università di Pavia) \\ Giovanni Crea \\ (Università di Pavia) \\ Angelo Cozzi \\ (Università di Pavia)
}

\# 146 (01-18)

Via San Felice, 5

I-27100 Pavia

economiaweb.unipv.it

January 2018 


\title{
Price Discrimination in the Italian Medical Device Industry: An Empirical Analysis
}

\author{
Cavaliere A. ${ }^{*}$, Crea G. ${ }^{\dagger}$, Cozzi A. ${ }^{\ddagger}$
}

November 24, 2017

\begin{abstract}
In this paper we carry out an empirical analysis to show that the significant price dispersion in the Italian market for medical devices may also be due to price discrimination strategies. We find that ASL (Aziende Sanitarie Lo-cali) incur higher costs than $\mathrm{AO}$ (Aziende Ospedaliere) that purchase larger quantities. Centralized purchasing agencies pay lower prices than single purchasers. Therefore second-degree price discrimination seems to be one cause of price differences. Product age has a negative effect on prices due to the impact of innovation on suppliers' costs. Concerning geographical price discrimination, public procurers located in the south pay significantly higher prices than those located in Northern or Central Italy. However we show that this result may be due to the higher probability that southern public procurers purchase from independent retailers rather than from producers of medical devices, implying a potential double marginalization effect due to the market power of retailers at a local level.
\end{abstract}

Key words: Price Dispersion, Bayesian Networks, Double Marginalization JEL Codes: I11, H51, L11

*Dipartimento di Scienze Economiche e Aziendali, Universita di Pavia email: alberto.cavaliere@unipv.it †Dipartimento di Scienze Economiche e Aziendali, Universita di Pavia email: giovanni.crea@unipv.it

$\ddagger_{\text {MA Università di Pavia }}$ 


\section{Introduction}

Since the onset of the European debt crisis, the topic of potential wastes of public resources has received particular attention in heavily indebted Member Countries such as Italy. One sector where inefficient use of resources may, due to its sheer size, have a large impact on total government budgets, is public healthcare.

Since a significant fraction of healthcare budgets is spent on the purchase of pharmaceuticals and medical devices, the last years have seen the introduction of several policies whose main purpose has been to identify potential savings and enforce cost reductions in these areas.

For the public acquisition of pharmaceutical products, this has been done, for example, by introducing policies that encourage the use of generics instead of brand products. The measures for medical technology procurement, on the other hand, have often focused on increasing the level of transparency in the rather complex and highly differentiated medical device markets ${ }^{1}$.

Part of the underlying reasons for the introduction of such measures has been the suspicion that there might exist a substantial level of price discrimination in the medical device industry. In other words, it is suspected that different public procurers have to pay significantly different prices for the acquisition of identical products. Unfortunately, the data made available by the Ministry of Health do not specify the name of the seller of the medical device and thus are useless to carry out an analysis of price discrimination. In this paper we try to carry out such an analysis by using a unique dataset that stems from the Consorzio di Bioingegneria e Informatica Medica (CBIM), a non-profit research institution that was founded in 1992 by the University of Pavia and a few scientific biomedical research institutes (see section four for more details). The main advantage of this data set is that both the seller and the buyer are specified for each transaction considered.

The paper is organized as follows. In section 2 we consider the definition of medical devices and market structure issues. In section 3 we list and discuss the potential key variables for price discrimination. In section 4 we precise the main features of the data set used for empirical analysis. In section 5 we consider some summary statistics to assess the degree of price dispersion in the market. In section 6 we carry out an econometric analysis by considering the potential variables for price discrimination analyzed in section 3. In section seven we carry out a Bayesian network analysis and get some further results about the causes of price dispersion, especially considering the geographical differences between Northern and Southern Italy. Some conclusions follow in section eight.

\section{Definitions and Market structure}

It is important to provide a definition of the products that are known as medical devices. The relevant definition for us is the one that is used for the Italian National Classification of Medical Devices (CND) from the Italian Legislative Decree n. 46 of February 24 (1997)

\footnotetext{
${ }^{1}$ For example, as pointed out in Ministero della Salute (2014), a direct informational flow from public medical device procurers to the Italian Health Ministry has been instituted in 2010, such that the latter does not anymore have to approximate the value of medical device consumption, but can assess it precisely at the device and hospital level
} 
where the definition of Article 1, §2 of the European Council Directive 93/42/EEC of June 14 (1993) is adopted.

It is very important to point out two general features that characterize the medical device industry: First, due to the complexity of the human body, the high number of different medical conditions and the diversity of treatment options, an immense variety of different products and technologies falls under the label of medical devices. Thus, there exists an extremely high level of product heterogeneity in this sector. Rather simple products, such as syringes or examination gloves, as well as high-end diagnostic imaging equipment or pacemakers, can be considered medical devices. Therefore, speaking of a medical device market may be misleading, at least under the common definition of market adopted in the industrial organization literature, which in most cases is based on demand and supply-side substitutability. The medical device industry consists of several different markets that, in turn, often include several submarkets. Therefore, one should speak of the market for drug-eluting coronary stents, the market for bicameral rate responsive cardiac pacemakers, the market for femoral head hip implants, etc. And of course, inside these submarkets, there can still be a high level of product differentiation along several, vertical or horizontal, dimensions. In many of these submarkets, the supply structure can, as suggested by Pauly and Burns (2008) and Vellez (2012) be described as a differentiated oligopoly By calculating the Herfindahl-Hirschmann Index (HHI) using data from 2003-2009 from the Orbis $^{\mathrm{TM}}$ database, Boscolo and Tarricone (2013) find that in most Italian medical device markets, market concentration seems to be increasing ${ }^{2}$.

The second important market characteristic is the high innovation rate. As Eucomed (2014a) reports, in 2013, there were 10,668 patent applications for products falling under the category of medical technology at the European Patent Office (EPO), thereby constituting $7 \%$ of all EPO patent applications more than for any other technical field. This is also reflected by the average length of the typical product life cycle, (the time span until a device is replaced by a new, improved product) of around 18-24 months Eucomed (2014a). This may certainly be a result of the substantial share of revenue that is spent on $R \& D$ activities. But, as both, Pammolli at all 2005 and Centro Studi Assobiomedica (2012b) point out, another cause for this high innovation rate might be the high level of knowledge base diversity in the medical device industry, implying a high level of interaction between different scientific fields.

Considering the demand side. we shall concentrate our attention on publicly procured devices. The Italian National Health Service, (Servizio Sanitario Nazionale or SSN) is a nationally coordinated but mainly regionally administered healthcare system. The system provides universal coverage that is mostly free of charge at the point of delivery. Despite the redistribution of funds by the central government, there exist significant regional disparities in the level of funding, especially between Northern/Central and

\footnotetext{
${ }^{2}$ The $\mathrm{HHI}$ is calculated as the sum of squared market shares $s_{i}$ on the $N$ firms in the market, i.e $\sum_{i=1}^{N} s_{i}^{2}$. Especially for very asymmetric distributions of market shares, the resulting $\mathrm{HHI}$ will be rather high, with a maximum value of 1 for a perfect monopoly. It should be noted, however, that the $\mathrm{HHI}$ measures market concentration, which is not necessarily accompanied by higher market power, i.e. the ability of firms to charge higher relative markups.
} 
Southern/Island regions. This is also reflected by differences in the efficiency of health-care provision and even the general health status of the population. In addition, there are significant patient flows from Southern to Northern regions, as well as a higher prevalence of private health facilities in the South that seem to cover needs that exist only to a lesser extent in other regions (Vellez (2012)).

\section{Key Variables for Price Discrimination}

In this paper, we try to find the empirically relevant determinants of medical device prices that are not linked to physical product characteristics. We shall call them external factors for convenience. Many such external price-influencing factors exist, both on the demand and supply side. In what follows, we shall explain some of them alongside the relevant literature, especially those that are important for our empirical analysis. In order to introduce more precision into the informal analysis, for some variables it might be useful to analyse whether and how they influence (i) supplier costs ${ }^{3}$, (ii) price sensitivity of the buyer, and the (iii) level of competition in the procurement procedure ${ }^{4}$. As we have already remarked the supply side of the medical device markets is often characterized by the existence of differentiated oligopolies, which can be described as a market structure where a rather small number of firms obtains some degree of market power through product differentiation. With the medical device industry being one of the fastest growing and most innovative in the Western world (Pammolli at all (2005)), this might partly stem from innovation and subsequent enforcement of market differentiation through patent protection rights. As it is well known in the price discrimination literature, a certain degree of market power is one of three conditions that needs to be fulfilled for price discrimination to be profitable. The other two are the existence of a segmentation mechanism and limited arbitrage possibilities for buyers. Both are met in a market environment where buyers are public entities and can be easily identified and segmented, for example along their available purchase histories, while arbitrage is hindered at least by information asymmetries and transaction costs. Another supply side characteristic is the existence of different supply chains that are used for transactions of otherwise identical medical devices. Most importantly, a device can be sold by a retailer or directly by the manufacturer. Price differences stemming from supply chain features could for example be caused by a double marginalisation problem or arise from bundling practices of a retailer, that a manufacturer might not be able to engage in. Differences between retail prices and direct manufacturer sale prices might, however, simply be a symptom of another important price determinant: the purchasing volume.

\footnotetext{
${ }^{3}$ according to Stigler (1987), whose definition is the one used in the relevant price discrimination literature such as Varian (1989), Tirole (1988), or Stole (2007). According to this definition a firm engages in price discrimination when it sells two similar products at price ratios that are not equal to the marginal cost ratios, i.e. when it charges different relative mark-ups.

${ }^{4}$ In this paper, we focus on publicly procured medical devices mostly due to space and data constraints but also because many privately paid-for medical devices are traded in rather standard product
} 
Quantity discounts are a form of second degree price discrimination, which differs from third degree price discrimination along the segmentation mechanism. The former implies segmentation of customers through an auto selection mechanism while the latter means sorting along observable buyer signals. In case of a non-monopolistic procurement market, one might suspect large quantities to be associated with a higher degree of competition in the procurement procedure. While this seems intuitive, the theoretical literature on this topic is more ambiguous, as pointed out in Vellez (2011) and Dimitri, Dini, and Piga (2006). While in models of exogenous participation higher quantity leads to more intense competition and lower prices, firms might abstain from participating in a tendering procedure when participation is endogenous and involves administrative costs. In this case large quantities lead to higher expected competition and, by reducing the probability of winning, push the expected net profit of participation below zero 5 . One could expect price differences due to quantity differences to arise also from cost effects, due for example to economies of scale in production. The argument put forward by Centro Studi Assobiomedica (2015b) and Eucomed (2014b), that large contracts might prevent small producers to participate in the competition due to capacity constraints, should be considered but not overemphasized, since such problems could be mitigated in several ways, for example through continuous delivery over the period of supply.

Closely related to the purchasing volume is the variable of procurement centralisation. As Sorenson and Kanavos (2011), and Eucomed (2014b) point out, there seems to be a Europe-wide tendency towards centralization of public medical technology procurement, probably due to increasing pressures on public healthcare budgets. As shown by Centro Studi Assobiomedica (2016), this is also true for Italy, where, between 2007 and 2015, for procurement above the EU-wide publication threshold of 207,000 Euro, centralised procurement went from $37 \%$ of contract values to $75 \%$ of contract value ${ }^{6}$. This study also finds that centralised procurement is generally related to larger contract sizes, which might be the most relevant determinant of the resulting unit prices of medical devices. However, a centralised regional procurement agency for medical devices might also be characterised by a higher level of specialisation with respect to procurement procedures and therefore able to make more objective and cost-efficient purchasing decisions. Also the "distance" between physicians and administrators is larger in case of centralised procurement, thereby reducing the influence of strong physician preferences, as explained in more detail below.

In case of single hospital purchasing, which represents the largest part of our data, there are several institutional factors that might be of interest when exploring the causes of price differences. First, there is the hospital type, which can take four forms in Italy: At the local level, the most important units are the Local Health Firms (Azienda Sanitaria Locale or ASL). Besides providing ambulatory and some community services, the ASL directly

\footnotetext{
5 These models, do, however, not take into account other, more dynamic factors that could potentially be relevant such as firms' general reluctancy to lose market shares in an uncertain future. For differentiated goods and physician preferences, winning a large procurement contract might also imply larger future profits from lock-in effects.

${ }_{6}^{6}$ This analysis is based on supply contracts exceeding the EU-wide publication threshold. Smaller contracts that are published only in Italy are excluded. The overall incidence of centralised procurement is therefore likely to be lower.
} 
manages one or more small District General Hospitals (Presidi Ospedalieri) and are mostly funded by the regional bodies. Funding is based on region specific diagnosis-related group (DRG) schemes (Ferré et all (2014)). In addition to the ASL, there exist three other types of healthcare facilities, that make up the level II hospitals. The most important type is the Hospital Trust or Azienda Ospedaliera (AO). AO are independent of the local ASL, directly accountable to the regions, and characterized by highly specialized departments that deal with more complex medical conditions than ASL. Furthermore ASL funding is mainly DRG based and $A O$ are generally reimbursed by a mixture of DRG-based and fixed-fee funding. The remaining two types are the Institutes for Treatment and Research (IRCCS) and the Teaching Hospital Trusts/Academic University Hospitals (AOU) that distinguish themselves from the AO mainly by their additional scientific research and/or teaching responsibilities. As pointed out in DiNovi at all (2017) concerning the creation of public independent hospitals $(A O)$ Regions have adopted different strategies. According to the percentage of beds within the hospitals controlled directly by ASL we can distinguish four models. 1) The integrated model, most hospitals are part of ASL the percentage of beds within the ASL hospitals is $>66 \%$. Six regions belong to this category: Veneto, Valle d'Aosta, Trentino Alto Adige, Abruzzi, Molise and Sardinia. 2) The semi-integrated model, the percentage of beds within the ASL hospitals ranges between $40 \%$ and $66 \%$. Piedmont, Emilia Romagna, Tuscany, Liguria, Umbria, Marche, Basilicata, Calabria and Apulia belong in this model. 3) The semi-separated model is characterised by a percentage of beds within the ASL's hospitals ranging from $20 \%$ to $40 \%$. Four regions can be identified within this model: Friuli, Lazio, Campania and Sicily. 4) The separated model, less than $1 \%$ of the hospitals are part of the ASL, and patients are free to select their providers (public or accredited private). The only region that falls into this category is Lombardy.

Besides the hospital type, and different regional model it could also be important to look at variables such as the size of the health firm, for example measured through the number of beds. Another important institutional characteristic is the distribution of power inside the hospital regarding the acquisition of medical devices. Hospital administrators may have different preferences than physicians, especially in terms of price sensitivity. However the relationship between these two types of actors is characterized by asymmetric information about product characteristics and final decisions are often made on the basis of the recommendations of less price sensitive physicians. The distribution of power between these two types of staff could therefore give an indication on the price sensitivity of the whole purchasing entity. As a first simple approximation, one could use the percentage of the health firm's staff holding an administrative position, as done in Bonaccorsi at all (2000) or Vellez (2012). More generally, physician preferences and their impact on the final purchasing decision and prices have been a focal point of several works, such as Burns and Lee (2008), Pauly and Burns (2008), Lerner at all (2008), or Grennan (2013). In general, if physicians have strong preferences for certain products (so-called physician preference items) and enough power to heavily influence the final purchasing decision, this can lead to high switching costs and lock-in effects for the hospital, implying a rather 
inelastic demand for these products ${ }^{7}$. If suppliers are aware of the inelastic demand function, due to the public availability of a hospital's purchasing history, they can engage in third degree price discrimination and charge higher prices to these customers.

Another variable that needs to be included into any analysis comparing prices paid by health firms across Italy is the region or macroregion where the buyer is located. As already said above, the DRGs used to fund hospitals differ across regions. Since several of these DRGs include also the use of medical devices, DRG differences across regions are likely to have an impact on the prices that hospitals are able to pay. In addition, there is a range of political, socioeconomic and cultural factors that might influence the prices paid for medical devices across different regions.

One channel through which such regional price differences might operate are late payments. This practice that many Italian public procurers engage in, is one of the factors that is frequently highlighted by the industry (Assobiomedica), as being a legitimate reason for price differentiation. With a national DSO (Days Sales Outstanding) average of slightly less than a year, Italy still lags far behind most European countries that have average national DSO measures of under 60 days, other exceptions being Greece, Spain and Portugal (Centro Studi Assobiomedica (2014)). Several explanations have been offered for this phenomenon, the most relevant being liquidity problems, inefficiency of the public administration and extremely long durations of legal procedures in Italian civil law, that may discourage suppliers to take legal action against illicit public practices. It should be noted that, even though DSO under 60 days are rarely observed in Italy, there are strong regional disparities and even stronger disparities at the local level. For example, while the average DSO of the regions Valle d'Aosta, Friuli Venezia Giulia, Marche, Lombardy and Trentino Alto Adige were ranging from 72 to 92 in December 2013, the average DSO of the regions of Calabria, Molise and Campania were 832, 822 and 456, respectively. In fact, one could imagine that default risk, opportunity costs and liquidity constraints will increase expected supplier costs for firms selling to hospitals with large DSO figures, which might lead to firms increasing prices or abstaining from competition. It should be noted however that price differences based on expected cost differences can be "justified" and do not fall under the definition of price discrimination. As Assobiomedica (2010) argues, it is important to include into any price dispersion analysis whether a certain device represents a recent innovation or whether it is on the market for many years, since more innovative products will naturally have higher prices. And in fact, given the highly innovative nature of the medical device

\footnotetext{
${ }^{7}$ It should be noted that the underlying reasons for such strong preferences can be of legitimate, but also illegitimate nature, such as corruption. Also the practice of sponsoring physician congresses in attractive locations and paying for some of the doctors expenses might be able to shift preferences. In some cases, it is not entirely clear where marketing methods end and more illicit practices begin. This topic is, however, goes beyond scope of this paper
} 
markets, this is an important variable that needs to be included into any analysis that compares prices of physically equal devices over certain period of time. While the product characteristics per se do not change, the buyers' perception of these characteristics varies over time, subject to the introduction of new substitute products. However large part of "intertemporal" price differences might also stem from different degrees of market power of the producer over time and hence price discriminatory practices. This is especially true for those innovations that are "disruptive" and open up a new (sub-)market.

Finally, there is a range of other factors that can influence price dispersion, which, due to data constraints or by their very nature, cannot be included into our empirical analysis. One factor is market transparency, whose impact on prices has been studied and debated in the US following the introduction (but not adoption) to Congress of the Transparency in Medical Device Pricing Act, which would have dictated mandatory disclosure of average and median product prices (see Grennan (2013) and Pauly and Burns (2008)). While in general, price transparency might lead to more uniform prices through a range of channels, the impact on welfare is ambiguous. Closely related is also the variable of collusion, which is generally facilitated by transparency as Hahn, Klovers, and Singer (2008) point out. Whether and how collusion is present in the Italian medical device markets is difficult to assess, however, and goes beyond the scope of this paper.

\section{The Data Set}

The dataset that is used stems from the Consorzio di Bioingegneria e Informatica Medica (CBIM), a non-profit research institution that was founded in 1992 by the University of Pavia and a few scientific biomedical research institutes. To build that database CBIM engage in web-based market research using the published final results of procurement procedures of different public bodies from the years 2010 to 2014, and save the collected pricing data in an internal database. Due to an institutional arrangement with the Department of Economics and Management of the University of Pavia, this internal database has been made available for our empirical research on price discrimination in the Italian medical device market.

The biggest advantage of this data is its highly disaggregated nature that is unmatched by any other source that has been used for similar empirical research in Italy. There are three levels of product aggregation that are included in the data: The national classification of medical devices (CND), the code of the national inventory of medical devices Repertorio dei Dispositivi Medici (RDM) and the device ID that CBIM has assigned to each medical device. The CND is a code starting with a letter, say $C$ for cardiocirculatory devices, to which additional 2-digit sequences are added for an increasingly refined grouping of products, such that we have C01 for arterio-venous devices, C0104 for angiography and hemodynamic devices, etc., until we reach the most disaggregated stage of, for example, C010402020101 denoting vascular dilatation balloon catheters for percutaneous transluminal angioplasty (PTA), a product group that constitutes the by far most frequently occurring type of medical device in our dataset with 1,585 of the total 7,612 observations. 
The most precise 11-digit $C N D$ code already provides a disaggregation level that is superior to that used, for example, in the empirical analysis of Vellez (2012). If one wishes to further disaggregate, the RDM code should be used. These simple numerical codes are assigned in a consecutive manner to every new entry in the Italian Health Ministry's inventory of medical devices that has been opened to the public in 2009 and is still continuously updated. A RDM code identifies a single product or brand of medical device of a certain producer and is already rather precise in most cases. While sometimes the disaggregation level of the RDM and the CBIM product ID coincide, for many products there are multiple IDs assigned to one RDM code.

The data were roughly divided into two similar opposable parts due to the nature of the BPA service ${ }^{8}$. On the one side, the data included details about the party requesting the service from CBIM, such as the name of the requesting hospital, the date of the request and, most importantly, the ID of the devices of interest, and, in the case of an ex post analysis, the offered prices, the supplier and, unfortunately very rarely, the associated quantity. On the other side, mirroring this data, we have the detailed results of the market research with the observations for the procuring entity, the source document, the device ID, the prices paid, the supplier, and, again very rarely, the quantity.

These two sides of the data were then linked by an additional datasheet providing detailed information about the product in question, most importantly the trade name of the device, the CND code, the RDM code, and the producer of the device. Using diverse IDs that identify the products, the requests or the sources, we have linked these datasets and created one large dataset. This data set was still in the opposing form of prices paid by the requesting entities and the prices identified by the market research, that were paid by different health procurers for the same products. However, in this form, there was often only one observation per medical device at the ID level with one price observed during the market research and one price being the price proposed to the health firm requesting the BPA service. In order to increase the number of usable observations, i.e. medical devices with at least two price observations, we replicated the dataset and appended it to the original one, in order to create an aggregated price variable that consists either of the prices revealed by market research or of the prices that were offered to the (ex post) BPA requesting entities. While this increases significantly the number of devices for which a price comparison is possible - from 1,161 to 2,886 - and the total number of usable observations - from 3,072 to 7,612 - it might come with a slight loss of precision as far as the interpretation of the price variable is concerned. This is because, as already mentioned, the prices from the health firms requesting the BPA service are not final prices but somewhat preliminary price offers that may be renegotiated if they turn out to be highly unfair. Furthermore, it might be the case that especially those health

\footnotetext{
${ }^{8}$ Benchmarking Prezzi e Acquisti (BPA). For this service, healthcare providers approach CBIM with a detailed list of medical devices that they either plan to purchase, or for which a preliminary procurement procedure has already been carried out, with the aim of acquiring information about prices that other healthcare providers have paid for these devices in the last 36 months
} 
firms that expect the prices offered to them to be too high are willing to pay for the BPA service, thus possibly leading to a sampling bias.

We solve this tradeoff by creating a dummy variable that identifies whether an observed price is a final price discovered by market research or whether it constitutes a preliminary price offer. As can be seen below, we then use this variable to check for robustness of the results from using a measure of the aggregated price as a dependent variable ${ }^{9}$. Basically, we construct three different types of dependent or target variables with several different specifications for each type: The first type is the intragroup coefficient of variation (CV), i.e. $\boldsymbol{C V}=\frac{\sigma_{j}}{\boldsymbol{\mu}_{j}}$ with $\boldsymbol{\sigma}_{j}$ denoting the standard deviation and $\boldsymbol{\mu}_{j}$ denoting the mean of the prices observed for one specific medical device $j$. At the individual level, the resulting values are often meaningless due to the low number of observations per group, but when averaging across all devices, we are able to infer interesting insights on the average level of price dispersion in the medical device industry, as can be seen in the summary statistics provided in the next section. In order to check these results for robustness, we constructed intragroup CV variables for market research prices only, as well as for slightly more aggregated medical device groups at the RDM level, i.e. at the level of a certain product brand of a certain manufacturer. Furthermore, for each of these specifications, we built the same variables containing observations only when the groups are over a certain size threshold, for example at least 3 observations at the ID level or at least 10 observations at the RDM level.

The second type of variable denotes the relative difference of a certain observed price to the intragroup mean in percentage. In mathematical notation, the percent above Mean (PAM) variable is given by $P A M_{i}=\frac{p_{i j}-\mu_{j}}{\mu_{j}}$ with $p_{i j}$ denoting a single price observation $i$ for a medical device $j$. The first advantage of this construction is that, due its relative nature, it captures all the product specific influences on prices and thus enables comparisons between entirely different groups of products. The second advantage, compared, for example, to using the lowest intragroup price as a reference, is that the PAM measure will be distributed rather continuously around its mean which is approximately zero. This allows us to use simple OLS as an estimation method instead of having to resort to more complicated estimation procedures that often rely on stronger assumptions. Again, in order to check the robustness of the results, we constructed several PAM specifications, for RDM groups, for market research prices only, and for a minimum of intragroup observations for each of them.

The third and final type of price variable that we constructed is simply an indicator variable denoting overpricing whenever the observed price is above the intragroup mean, or, in other words, whenever the relevant PAM measure is larger than zero. While this

${ }^{9}$ The fact that at the ID level, only for 189 of the 2,886 comparable devices there are 5 or more price observations, seems to be a large problem at first sight. However, while this might leave us unable to make inferences about the extent of price dispersion and its determinants for a single medical device type, we can still make these inferences at an aggregated level by adequately constructing the dependent variable 
discretization naturally comes with some loss of precision, such an overpricing indicator is optimal for the Bayesian network analysis (section 7) given that this method only works with discrete variables.

Apart from the price variables it was possible to create an indicator denoting the existence of an independent intermediary in the supply chain while using mostly the original dataset. Since the database provided the name of the manufacturer, as well as the final seller of the device, it was possible to compare the names of the respective firms and set the value of the intermediary indicator equal to one whenever the producer and the final seller were not the same firm and to zero whenever the two values coincided. However, because it is sometimes the case that producers and suppliers belong to the same corporate group of firms but this is not evident from the denominations in the data, the supplier will be treated as an independent intermediary. Therefore, using public available information, we checked all distinct producer-seller pairs for such dependencies and corrected the values of the intermediary indicator accordingly.

All the other important determinants, however, could not be constructed using only the original dataset. Therefore, we used the variables showing the names of the procuring health firms to augment the dataset along several, mostly purchaser-related dimensions. First, research on the purchaser names yielded the type of hospital (AO, ASL, IR$\mathrm{CCS} / \mathrm{AOU}$ ) and the region where these health firms are located. This region variable was then used to create a variable denoting the greater geographic areas North-East, NorthWest, Center, South, and Islands, as well as a dummy variable taking the value 1 if the purchaser is located in the South or on the Islands. We also use the location information to create different dummies to identified regional organizational model: integrated, semiintegrated, semi-separated and separated. Furthermore, the region variable, together with the procurers' names was then used to create the code that is used by the Italian Health Ministry to identify its public health firms. This code was then used to augment the data along the dimensions of percentage of administrative personnel and number of beds.

In addition to these variables, we used the last four yearly publications of Assobiomedica on late payments of public procurers of medical devices to create a variable denoting the average DSO values of hospitals over the years 2011 to $2014^{10}$. One might object that it would be better to use the DSO values that stem from the months or year preceding the purchase and this would certainly be the best option if this data were available and trustworthy. However, since older data on DSO statistics on a monthly level is publicly available only at the regional aggregated level, the four data sources we use were the only ones that were easily accessible. Furthermore, it is important to use average data because, as Assobiomedica notes, the DSO statistics are calculated using only a panel of firms that are active on the Italian medical device market. The data can therefore be seen as representative only at the regional and national level, while DSO values at the single

10 The specific values we use are an average over September and October 2011, and the values of December 2012, 2013 and 2014. See Centro Studi Assobiomedica (2012a), Centro Studi Assobiomedica (2013), Centro Studi Assobiomedica (2014), and Centro Studi Assobiomedica (2015a). 
health firm level are possibly biased. Averaging over several years might partly solve this problem and in most cases the ordinal ranking across hospitals will be preserved. However, the resulting statistic might not perfectly represent the DSO value that the sellers might have included in their pricing strategies at the time of the procurement procedure. Thus, the results from the DSO variable, while still being meaningful, have to be interpreted with some caution and the construction of the variable should be further refined in subsequent research activities. A good solution would, for example, be to receive the monthly DSO data from Assobiomedica for the years 2009 to 2014 and compute the averages for the last two years before the purchase was made.

Another constructed variable that will be included in our analysis is the one denoting how long a device has been included in the national inventory for medical devices. This variable has been created by merging the date of first publication in the RDM database to our dataset and calculating the number of days that have passed between this first publication and the observed purchase. Because only the same devices should be compared to each other, also in this case it is useful to create a relative variable denoting how much longer the device has been in the RDM database compared to the average across observations for this device. The goal of including this variable was to create a proxy for the innovation or the age of a product, a possibly significant factor in explaining price dispersion. However, it is certainly not a perfect proxy due to several reasons. Because the RDM inventory has been implemented rather recently

with the first entries starting in July 2007 , especially for the older products, the date of first publication in the inventory is not necessarily related to the date of first market introduction. Given that more than half of observations with entries for the first RDM registration date are collected in the initial period between mid-2007 and end of 2009, this may be rather relevant in our case. Also for more recently introduced products there may be a delay between market introduction and registration in the inventory, something that is also reflected by the existence of (very few) negative values of the product age proxy, which have been set to missing. However, the construction of the relative age difference variable might mitigate both types of problems to some extent. In the first case, the older products that were included in the database between 2007 and 2009 will have a larger average age (our data stems almost entirely from the years 2011 to 2014) and thus the value of the relative age difference variable, that is calculated likewise to the PAM variables from above, will be weighted downwards. Also for the second type of problem, the variable retains its explanatory power as long as the delays between product introduction and product registration are not too different across devices. It should also be mentioned that we will include yearly dummies (2010-2014) in some of the specifications in order to eliminate the possibility that the relative age variable (or the DSO variable) captures some underlying time related macro effects ${ }^{11}$.

Finally, a centralization dummy has been created because some observations of purchases by more centralized public procurers are included in our dataset. They include

\footnotetext{
${ }^{11} \mathrm{Apart}$ from such robustness checks, we shall generally disregard the time dimension in our analysis because we treat the data as pooled cross section. There is no need to treat it as a panel dataset since the data was sampled over a time span and does not follow specific procurers over the already relatively short period from 2010 to 2014 .
} 
agencies such as So.Re.Sa. the regional procurer of the region Campania, the three institutionalized purchasing unions of Tuscany, Estav Centro, Estav Nord Ovest and Estav Sud Est, or the Federazione Sovrazonale Piemonte Sud Est, one of six purchasing unions active in the region Piedmont. However, these types of procurers account only for 276 of the 7,612 observations and thus a distinction between regional procurers and purchasing unions such as in Centro Studi Assobiomedica (2015b) as not been considered. Furthermore, since most other explanatory variables do have missing values if the purchasing entity is a centralized procurer, the variable has to be dropped for the main OLS model and the Bayesian network analysis. However, because preliminary OLS regression results suggest that this centralization dummy has a very large and significant negative effect on prices that is also robust to all PAM specifications.

Before concluding this section, some remarks on the quantity variable should be made. The quantity of purchased products or the size of a specific lot in the procurement procedure will very likely have a significant impact on prices and probably be correlated with many other explanatory variables, such as the level of centralization, the hospital type or the hospital size. Therefore, excluding quantities but including covariates that are correlated with the quantity variable might lead to an endogeneity problem in form of an omitted variable bias. However, we have only 626 non missing observations for our quantity variable and because most of these observations do only occur a single time per medical device (both at the CBIM ID level and the RDM level), we have a maximum of 95 comparable observations that we can use in a single regression model. When we include additional variables that may have some missing, this number reduces further. Even though such a single regression analysis confirms the expected negative effect on prices, it should be interpreted with caution due to the low number of observations. Because the quantity variable cannot be included in the main analysis, we have checked the sample correlation between all the explanatory variables and the quantity variable to assess the severity of a possible omitted variable bias. As it turns out, the correlation coefficient never exceeds an absolute value of 21 percent for the AO dummy and is much lower in most cases. Only for the centralization variable, the one for which we would expect the strongest relationship, such an analysis was not possible, because of the low number of positive observations. To sum up, even though not including the quantity variable in our analysis might lead to an omitted variable bias, this bias does not seem to be extremely strong as long as we do not include the centralization variable, which we will not in the main analysis.

\section{Summary statistics}

In this section, we would like to provide an overview on the value distributions of the most important variables that have been introduced in the previous section.

First, we should take a look at the distribution of the intra-group coefficients of variation of the prices paid. Figure 1 provides an overview on the distribution of these coefficients for four different specifications of the variable. Figures (a) and (b) show the distribution of intra-group CVs at the CBIM ID and the RDM level, respectively, with a minimum 
requirement of at least two comparable observations. Figure (c) is equivalent to (a) but only observations from market research were used, i.e. prices that were offered to the parties requesting the BPA service were excluded. Figure (d) shows the distribution of intragroup CVs at the RDM level for those devices with at least 10 comparable price observations.

As already mentioned in the previous section, while some individual CV values, especially for figures (a), (b) and (c) might not be that meaningful due to the low number of observations per group, the distributions, the average values (solid lines), and the median values (dashed lines) certainly provide a better picture about the prevailing level of price dispersion in the medical device industry. As can be seen, the distributions are rather similar with average values ranging from 16 to 22,5 percent and median values ranging from 12,5 to 18 percent. Comparing figure (d) with the other figures, it seems that the low number of intra-group observations for some of the values in the other figures does overestimate the level of price dispersion. On the contrary, when including all and not only the frequently occurring RDM observations, as done in figure (b), the resulting price dispersion seems to be lower on average. Interestingly, this seems also to be the case when excluding the prices offered to the BPA requesting parties, which may hint at a certain self-selection into this service of health firms that are offered outlying prices. In general, however, the similarity of all four figures indicates that there exists a significant level of price dispersion in many medical device markets.

Because our data is rather unevenly distributed across device types, producers, public procurers, and regions, it is also important to provide an overview on the most frequently occurring values of these variables, which will be done in the following tables.

Table 1: Description of the most frequently occurring CND codes at the most disaggregated and the more aggregated 5-digit level.

\begin{tabular}{l|l|c} 
CND code & CND description & Obs. \\
\hline C010402020101 & Vascular dilatation balloon catheters, PTA & 1,585 \\
P0704020103 & Coronary artery stents, drug eluting (DES) & 623 \\
C010401020101 & Angioplasty catheters, baloon dilatation, coronary & 498 \\
P0704020201 & Peripheral arteries stents (BMS) & 408 \\
C0104020203 & Embolization implants and systems & 260 \\
$\vdots$ & $:$ & $\vdots$ \\
\hline \hline 5-digit CND & Description & Obs. \\
\hline C0104 & Angiography and hemodynamic devices & 3,045 \\
P0704 & Vascular and cardiac endoprostheses & 1,649 \\
C0402 & Peripheral vascular guidewires & 194 \\
C0502 & Cardiovascular introducing sheaths, valvulated & 165 \\
C0401 & Coronary artery guidewires & 160 \\
$:$ & $:$ & $:$ \\
\hline \hline Total CND obs. & & 6,042
\end{tabular}




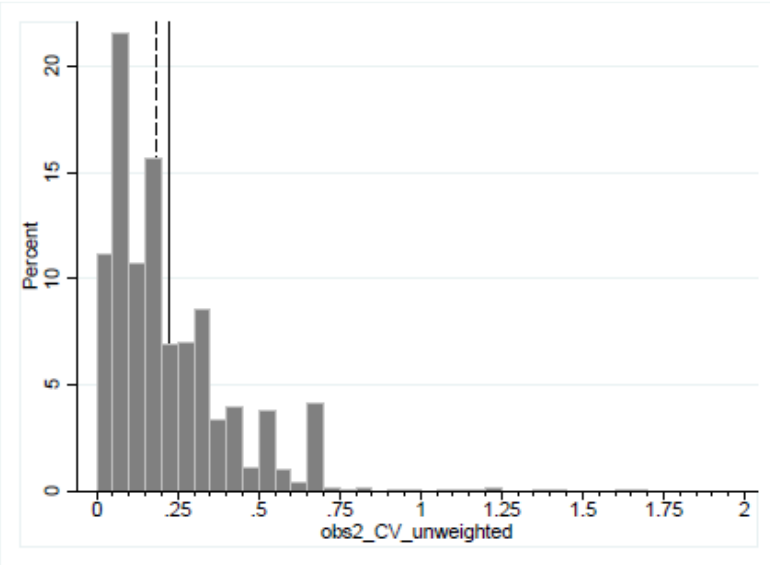

(a)

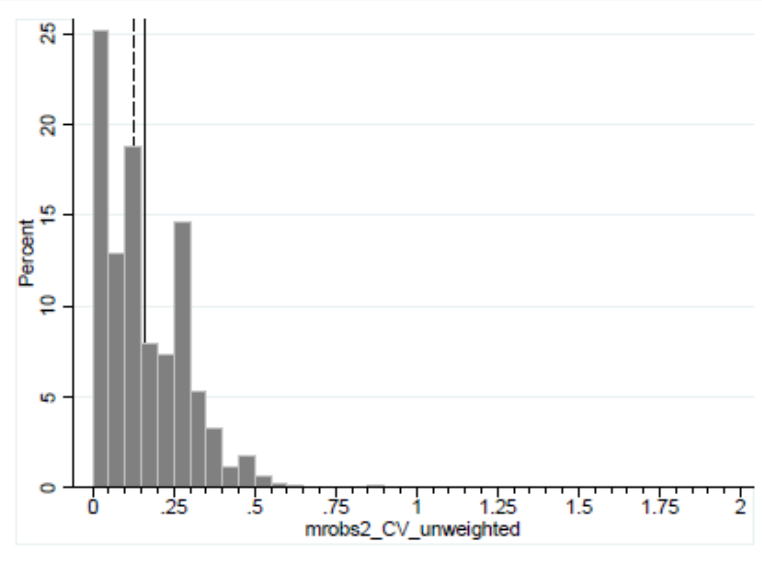

(c)

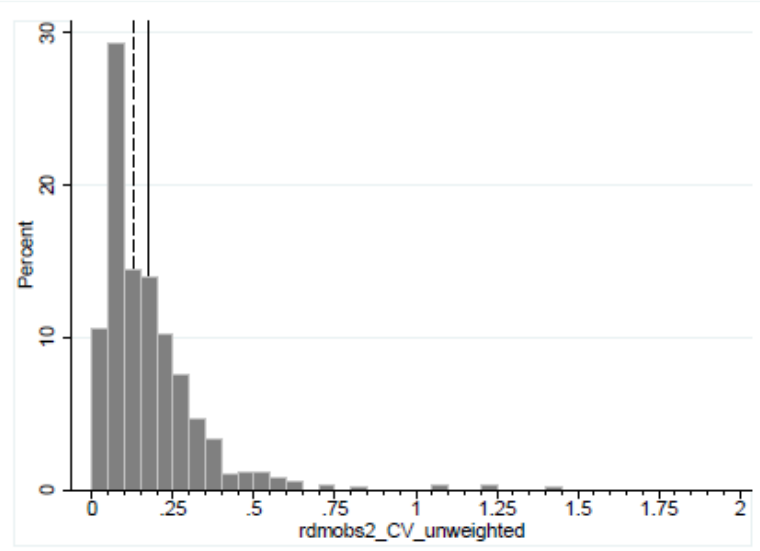

(b)

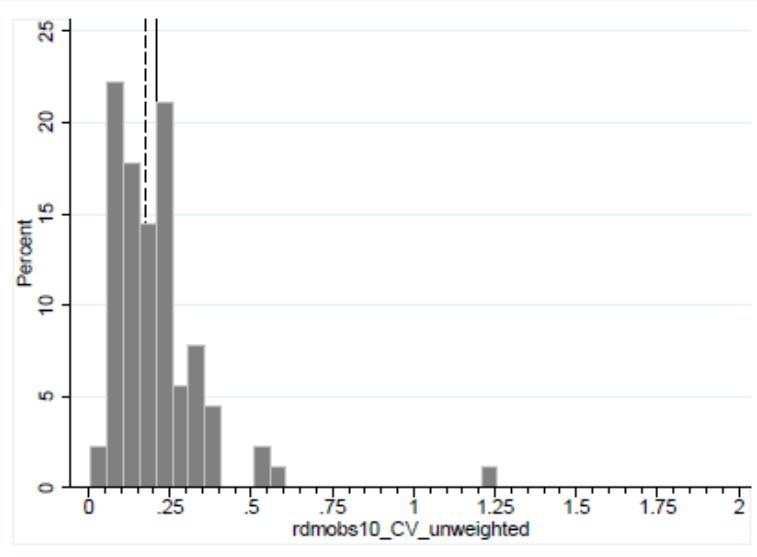

(d)

Figure 1: Distributions of different specifications of intragroup coefficents of variation of medical device prices. The solid lines represent the average values, while the dashed lines represent the median values.

First, it is important to take a closer look at the types of devices we are mostly dealing with, i.e. the most relevant medical device markets in our analysis. The upper part of Table 1 shows the 5 most frequently occurring CND codes (the data contains 173 unique CND codes) at the most precise level, while the lower part shows the same statistic for the more aggregated CND level of 5 digits. As can be seen, all of our most frequently occurring devices are products that are used by surgeons, especially for the treatment of cardiocirculatory diseases. Because only 6,042 of our 7,612 total observations include a CND code, displaying the relative amount of observations that these types of products represent is not entirely precise, but one could say that the devices in the upper part of Table 1 represent at least $44 \%$ of our observations while the top 5 device types at the more aggregated level below represent even more than $68 \%$ of our total observations. Since all these devices are of rather high complexity whose assessment of advantages and disadvantages will vary across surgeons and doctors using them, it is likely that the theoretical considerations on physician preference items are very relevant in our case. In 
addition, as far as future research is concerned, the large number of observations for certain device types also allows for a more detailed analysis of specific markets. Of course, this concentration of our data on certain medical device markets also implies a concentration of our observations on those producers and suppliers that are specialized in these types of devices. Table 2 shows the top 10 of most frequently occurring producers and suppliers in our dataset. As can be seen, the three most prevalent firms lead both categories in terms of frequency although the gap to the following firms is much lower for the final suppliers.

Table 2: Top 10 most frequently occurring producers and final suppliers in the dataset. The company names have been anonymized (and replaced with an ID number) due to a non-publication agreement with CBIM.

\begin{tabular}{lc||lc} 
Producer name & Obs. & Supplier name & Obs. \\
\hline Anonymized firm ID001 & 1,492 & Anonymized firm ID001 & 989 \\
Anonymized firm ID002 & 1,312 & Anonymized firm ID003 & 822 \\
Anonymized firm ID003 & 1,236 & Anonymized firm ID002 & 714 \\
Anonymized firm ID004 & 378 & Anonymized firm ID011 & 479 \\
Anonymized firm ID005 & 372 & Anonymized firm ID012 & 322 \\
Anonymized firm ID006 (ID010) & 321 & Anonymized firm ID010 & 290 \\
Anonymized firm ID007 & 163 & Anonymized firm ID013 & 255 \\
Anonymized firm ID008 & 140 & Anonymized firm ID014 & 219 \\
Anonymized firm ID009 & 126 & Anonymized firm ID015 & 207 \\
Anonymized firm ID010 & 126 & Anonymized firm ID007 & 163 \\
$:$ & $:$ & : & $:$ \\
\hline Total obs. & 6,787 & Total obs. & 5,651
\end{tabular}

Similar to the device types and the supply side, our data are also unevenly clustered around some public procurers that account for a large part of our observations as can be seen in Table 3, listing the 10 most frequently occurring procurers. Of the 125 distinct medical device procurers in our dataset, the 10 most frequent account for more than 70 percent of the observations and the most frequently occurring purchaser, the Anonymized procurer ID101 from Sicily, accounts for nearly a third of all observations. This is because this AO, together with the Anonymized procurer ID103, which is number 3 on the list, are the two hospitals that repeatedly requested the BPA service from CBIM after they had received their purchase price offers. This clustering of the data needs to be kept in mind when engaging in statistical inference, as will be explained in more detail in the next section. The skewed distribution of observations across Italian hospitals naturally affects the outcomes of the other purchaser-related determinants, such as the region variable, which is illustrated in Table 4 together with the frequencies of the associated macroregion. As can be seen, the two most represented regions in our dataset are Lombardy and Sicily, as well as their associated greater regions North-West and Islands. 
Table 3: Top 10 most frequently occurring public procurers of medical devices in the dataset. The company names have been anonymized (and replaced with an ID number) due to a non-publication agreement with CBIM.

\begin{tabular}{|c|c|c|c|c|}
\hline Name & Type & Obs. & Percent & Cumul. \\
\hline Anonymized procurer ID101 (BPA) & $\mathrm{AO}$ & 2,353 & $30.91 \%$ & $30.91 \%$ \\
\hline Anonymized procurer ID102 & IRCCS & 473 & $6.21 \%$ & $37.13 \%$ \\
\hline Anonymized procurer ID103 (BPA) & AOU & 466 & $6.12 \%$ & $43.25 \%$ \\
\hline Anonymized procurer ID104 & AO & 419 & $5.50 \%$ & $48.75 \%$ \\
\hline Anonymized procurer ID105 & $\mathrm{AO}$ & 390 & $5.12 \%$ & $53.88 \%$ \\
\hline Anonymized procurer ID106 & $\mathrm{AO}$ & 359 & $4.72 \%$ & $58.59 \%$ \\
\hline Anonymized procurer ID107 & $\mathrm{AO}$ & 351 & $4.61 \%$ & $63.20 \%$ \\
\hline Anonymized procurer ID108 & IRCCS & 296 & $3.89 \%$ & $67.09 \%$ \\
\hline Anonymized procurer ID109 & $\mathrm{AO}$ & 240 & $3.15 \%$ & $70.24 \%$ \\
\hline Anonymized procurer ID110 & ASL & 179 & $2.35 \%$ & $72.60 \%$ \\
\hline & & & & \\
\hline Total & & 7,612 & & $100 \%$ \\
\hline
\end{tabular}

However, in the case of Sicily (and also its macroregion Islands), the data stems almost completely from the Anonymized procurer ID101 and are therefore not representative of the region or the macroregion. Since this is also the case for regions such as Apulia and Marche, we limit our analysis of the impact of geographic provenance on building a dummy that equals one if a medical device procurer is located in the greater regions South or Islands, which is the case in 3,299 of 7,312 observations. Finally, before concluding this section, we present an overview on the remaining purchaser related variables, i.e. the type of public procurer, the percentage of administrative staff, the size in number of beds, as well as the DSO statistic in Table $5^{12}$. Some interesting insights can be drawn from this table: First, our dataset is heavily skewed towards $A O$ that represent around two thirds of all observations. Second, these AO employ significantly lower amounts of administrative staff and are significantly smaller in number of beds than IRCCS or ASL. While this might seem counter intuitive at first sight, it should be noted that while AO generally consist of one or very few specialized hospitals, ASL generally includes several local hospitals and other communal healthcare providers. In addition, one could imagine that, because of the distinction between $A O$ and IRCCS/university policlinics, the $A O$ variable may often capture those hospitals that are too large to be managed by an ASL as a communal hospital, but too small or not important enough to serve as a research and teaching hospital ${ }^{13}$. Finally, given that the Anonymized procurer ID101 is rather small with [400-800] beds, this might imply a somewhat biased distribution due to our sample. However, not including this AO into our analysis increases the average bedsize only to [700-750] and thus, the large difference still remains. As far as the DSO statistic is concerned, there does not seem to

\footnotetext{
${ }^{12}$ we will omit summary statistics of the relative age difference variable since it is, similarly to the price PAM variables, centered around an average of about zero with $99 \%$ of the values in the range of $-80 \%$ to $+80 \%$.

${ }^{13}$ As a side note, because of the rather low number observations and because IRCCS and university $\mathrm{AO} /$ policlinics seem sometimes to be overlapping, we did not create distinct variables for these two hospital types
} 
be an extremely strong connection between procurer type and late payments. However, as expected, such a correlation exists when comparing the average DSO statistic of the South and Islands with those of the North and Center, where the average in the North/Center is around 138 days, while it lies at 354 in the South/Islands.

\section{Econometric Analysis}

The following analysis is divided into two parts: The main OLS estimation, whose results from different specifications are provided in Table 6 and Table 7, and an additional OLS regression model that includes the centralization variable, which is provided in Table 8. Both models are simple linear equations including the variables displayed in the respective tables.

Before interpreting the results from Table 6 and Table 7, two remarks need to be made. First, the list of specifications that we provide is no exhaustive and has been backed up by several additional specifications that provide similar results ${ }^{14}$, especially for those variables with significant effects throughout regressions (1) to (5) and (6) to (9). Second, we use clustered standard errors at the procurer level that are provided by the Stata ${ }^{\mathrm{TM}}$ software package in our analysis. This seems reasonable because our data is distributed across a limited number of device procurers whose unobserved institutional characteristics, such as the influence of physician preferences in the final decision, may very well have a significant impact on final prices. If we do not account for these unobserved cluster effects, i.e. treat all observations as being independent, the standard errors of our variables, especially of those at the cluster level, such as administrative staff or number of beds, will be severely underestimated and the null hypotheses will be rejected too often. One might argue that our data is not only clustered around procurers but also around producers, suppliers and medical device types. Two remarks can be made here: First, the specific product characteristics are mostly canceled out by the way the dependent PAM variables are constructed and therefore unobserved factors related to device types will probably play a minor role in this analysis. Second every firm has an incentive to engage in price discrimination in order to increase its profits. Thus, the impact of unobserved producer or supplier characteristics on final prices is likely to be much smaller than the impact of the unobserved characteristics of the procuring health firm.

In table 6 we use the south/Island dummy and in Table 7 we use the Regional organization type dummies (Integrated, semi-integrated, separated and semi-separated) we cannot use the Regional organization type and the south/island dummy in the same model given the hight correlation between dummies ${ }^{15}$. Table 6 shows five different OLS regression specifications using four different dependent variables. The first specification uses the CBIM ID to define groups of comparable medical devices and includes all observations with at least two devices per group. It should be noted here, that, although only 4,623 observations are included in this estimation, there are 7,612 observations of devices meeting this criterium. Unfortunately, only 4,623 observations have nonmissing values for all explanatory variables included in the regression equation. The second equation also

\footnotetext{
14 The estimations are available under request

${ }^{15}$ Correlation between semi-separated dummy and south is 0.8
} 
uses the CBIM ID as dependent variable, but includes only devices where at least 3 comparable observations are present in the dataset. Furthermore it includes yearly dummies, mostly in order to eliminate the possibility that the relative age variable captures effects related to the year the purchase was made. The third and fourth specification use all comparable devices with at least two observations at the RDM level, i.e. at a slightly more aggregated stage. Specification (1) and (4) include an additional dummy variable denoting whether the observed device procurer is one of the two entities that have requested the BPA service from CBIM. This is done in order to assess the possible influence of the preliminary nature of prices offered to these firms. Finally, in the fifth specification we use only those devices where at least 10 comparable observations are available at the RDM level in order to check for eventual biases arising from the sometimes low number of comparisons in the other specifications.

As can be seen, there are several variables that are highly significant throughout the different specifications. Starting from the top, the dummy denoting whether the observed health firm is an ASL seems to have a significant positive impact on prices paid compared to the baseline case of the procurer being an $\mathrm{AO}$, and increases the PAM measure on average by 7.25 to 19.61 percentage points, depending on the specification. On the other hand, it seems that IRCCS or university AO/Policlincs do not have to pay prices that are significantly different to those paid by regular $\mathrm{AO}$. As far as the geographical provenience of the procurer is concerned, it seems that medical device purchasers located in the macroregions South or Islands do have to pay significantly higher prices, that are, on average, up to $38 \%$ higher than the corresponding intragroup mean. However, as can be seen in specification (1) and (4), these results have to be somewhat qualified since a part of this effect may stem from the fact that both our BPA service requesting entities are located in the South/Islands macroregions. While the South/Islands dummy is still significant at the $10 \%$ level in specification (4), it is entirely insignificant in (1). This does not completely invalidate the result that Southern hospitals have to pay higher prices since these two health firms do in fact come from this part of ltaly, but it should be kept in mind that the prices underlying these results are partly of preliminary nature. While they may have been renegotiated afterwards, the significant effect of the BPA dummy at least shows that there seem to have been several attempts of overpricing practices against these firms ${ }^{16}$.

\footnotetext{
16 As far as the reduced significance level is concerned, this could also stem from an increase of multicollinearity when the BPA dummy is introduced into the analysis. In fact, in specification (1), the variance inflation factor (VIF), a measure for multicollinearity (see Wooldridge (2009)), of the South/Island dummy increases from around 6 to 24 when the BPA dummy is introduced (whose VIF measure then lies at around 17). This is a level where a meaningful interpretation of the significance of these coefficients might no longer be truly possible. While multicollinearity does not reduce the explanatory power of the whole model per se, it inflates the coefficient variances and thus tends to make significant coefficients insignificant. Besides the BPA dummy, it is mainly the South/Islands dummy and the DSO variable, whose VIF measures are sometimes around or higher than the rule-of-thumb limit of around 10, above which further investigation may be needed. However, because the main risk that we face is that we underestimate the significance of our coefficients, due to space constraints, we shall abstain from further treatment of multicollinearity problems. Furthermore, the results
} 
Apart from a lack of robustness of the effect of late payments on prices, this effect seems to be rather small and, against the theoretical intuition, negative. The same holds for the impact of the hospital size in terms of number of beds. The effect is not robust to the different specifications provided here, as well as to additional specifications that are not included here, where an interaction term between the hospital types and size has been constructed. Also the impact of administrative personnel seems to be negligible. The dummy variable denoting whether an independent intermediary was part of the supply chain does not seem to be significantly larger than zero.

Finally, and somewhat surprisingly, given the approximative nature of the variable construction, the variable denoting whether and by how much a product is older relative to the other devices in the comparison group, is highly significant for all five specifications, regardless of whether additional year-of-observation dummies are included or not. The value of the coefficient ranges from -0.248 to -0.432 , which implies that on average, if a device is included $10 \%$ longer in the RDM inventory than the average in the comparison group, the resulting final price will be around 2.5 to 4.3 percentage points below the intragroup mean. This result is in line with the informal reasoning of section 2 where we suspected that devices that constitute a recent innovation, will be more expensive than older products because of several cost and non-cost related factors.

As a final remark to Table 6 , we should mention that the significant and seemingly strong effect of the Year 2010 dummy should not be overestimated. It is based on solely 57 positive observations with nearly half of them from a single procurer and might therefore simply represent an anomaly in the data distribution.

Table 7 shows four different OLS regression specifications using three different dependent variables. The first specification uses the CBIM ID to define groups of comparable medical devices and includes all observations with at least two devices per group. The second equation also uses the CBIM ID as dependent variable, but includes only devices with at least 3 comparable observations. The third includes yearly dummies. The fourth specification uses all comparable devices with at least two observations at the RDM level, as we said before this is a slightly more aggregated product specification. As one can check, in this specification the three different Regional organizations dummies have a negative impact on prices with respect to the baseline case: the semi-separated model. More in the detail, the separate organization model performs better, with an average reduction of PAM measure ranging from -34.02 to -21.93 . The other two regional models also predict a significant and negative effect on prices ranging from an average of -30.40 to -18.88 for integrated regional model and from -34.24 to -15.04 for semi-integrated regional model. When interpreting these results we have to consider that the observations for the separated model are collected in Lombardia (the only region characterized by this organization model), that account for 2586 out of 4017 observations collected in the north/center area. Also in the baseline regional organization model, the semi-separate one, 
Sicily and Campania account for almost all observations (2672 out of 2806) and again these two Regions account for 2672 out of 3299 collected in the south/island area. For that reasons we believe that the specification with regional models replicate, to some extent, the previous results obtained using the south/island dummy where we find evidence about higher prices in the south/island macro-region whit respect to the northern one ${ }^{17}$. The coefficient obtained from control variables in Table 7 confirm the result obtained in Table 6 .

Because of the important policy implications derived from finding a strong effect of centralized procurement on final prices, we have included this variable into the analysis, as shown in Table 8. Because of too many missing values, the (seemingly insignificant) variables percentage of administrative staff, number of beds, and intermediary have to be dropped for this analysis. In addition to the dummy denoting whether procurement was centralized, we have used this opportunity to include additional specifications of the PAM variables into our analysis ${ }^{18}$. The dependent variable in (10) and (11) compares devices with at least two observations at the ID level, while in specification (12) at least three comparable observations must be in the dataset to be included in the regression. Specifications (13) and (14) show the results using only data that were gathered during market research activity, i.e. excluding the preliminary prices of the BPA requesting entities, with (13) at the ID level and (14) at the RDM level. Finally, (15) uses all observations with at least two comparable devices at the RDM level.

Four interesting insights can be drawn from Table 8: First, because it is insignificant for all 6 specifications it seems that the coefficient of the ASL dummy variable is unfortunately less robust than the results from Table 6 would suggest. Second, medical devices that are purchased by a centralized procurer are significantly cheaper, on average, than those purchased by $\mathrm{AO}$ with an average PAM impacts ranging from -6 to -30 percentage points. It should be noted however, that these effects might not be pure partial effects but could include unobserved effects related to quantity and lotsize, as already explained.

Third, the coefficient of the variable denoting Southern or Island provenience is again significantly positive in most cases, except for those specifications where data from two BPA requesting entities are excluded, thus replicating the results from specifications (1) and (4) of Table 6.

Fourth and again surprisingly, the variable denoting product age seems again to be very significant and negative although the effect seems somewhat smaller ranging from an average of 1.8 to 3 percentage point reduction in the corresponding PAM measure for a product that is $10 \%$ older than the group average.

To conclude, we can say that our empirical results are mostly in line with the theoretical ones. The most robust results seem to be that prices decrease with product age and that prices paid by centralized procurers are lower than those of other procurer types. It also seems that prices paid by procurers in the macroregions South and Islands are higher

\footnotetext{
${ }^{17}$ It is also interesting to point out that this argument holds also for the comparison between the baseline model and the integrated and the semi-integrated ones. As both models perform better with respect the baseline one and still the observation for these two models come mainly from regions located in central and northern Italy ${ }^{18}$ For this analyisis, we dropped all observations with procurers being of the type other (not centralized) as specified in Table 5 in the previous subsection.
} 
than those paid in the other regions, although part of this effect may stem from the preliminary nature of some of the price data from these regions. Finally, as long centralized procurers are excluded from the analysis, ASL seem to pay higher prices than AO. All other variables, such as the DSO statistic, the number of beds or the percentage of administrative personnel do not seem to have a significant impact on final prices. As far as the answer to our second research question is concerned, it seems that only the variable approximating innovativeness might impact prices through (partly) affecting costs. The other significant variables (procurer type and region) on the other hand, seem to reflect characteristics that are more related to the price sensitivity of the purchaser or the level of competition in the procurement procedures.

\section{Bayesian Network Analysis}

The last empirical part of this paper will be concerned with learning a Bayesian network structure from the data in order to gather additional interesting insights. In general, Bayesian networks are probabilistic graphical models that explain relationships between certain random variables by using conditional independence statements.

Generally, while a deterministic model defines rules of interactions between variables that always hold, a probabilistic model will include rules of interaction between random variables that are not always true and whose outcome is subject to some uncertainty. Now we can introduce the idea of how to learn the network structure. When we have a (possibly large) dataset to our disposal, i.e. the only thing we know are the variables in our model, as well as a large number of different configurations of these variables. One of the main approach. In this case, is to construct a skeleton of a graph, i.e. the undirected structure of the Bayesian Network, learn the direction of the links between variables and assessing their strength, i.e. learning the parameters. The methods and algorithms that have been developed to deal with these kinds of problems can be divided in methods of constraint-based learning and score-based learning ${ }^{19}$.

It is now time to apply the Bayesian network framework to our case and learn a preliminary network from our data, one possible result being illustrated in Figure 2. Figure 2 has been learned from the data using a score based method (called "Bayesian Learning" by the GeNie software) after all variables have been discretized. While the score function that is used penalizes complexity, without further restrictions on the search space, the resulting graph is a nearly complete graph, i.e. nearly every node is directly connected to all other nodes. This is probably the case because of rather strong dependencies between the variables in our dataset. Since such a graph does not provide much additional insight into the relationships underlying our data, we have limited the search space to networks with a maximum of two parent variables per node and included additional logical constraints on the directions of some arcs.

As far as the discretization is concerned, we have used the standard PAM measure at the CBIM ID level (as, for example, in specification (1) in Table 7) to create a dummy variable

${ }^{19}$ For complete overview of Bayesian network analysis see Nielsen and Jensen (2009) 
denoting overpricing whenever the PAM measure is larger than zero. The same has been done for the variable denoting the relative age difference of a device in its comparison group, where we created a dummy variable denoting whether a device is older than the intragroup average or not. While the discretization for these two variables is straightforward, the categorization of Average DSO, Percent of administrative personnel and Number of beds could have been done in many different ways. We have decided to limit ourselves to two values per variable, with thresholds that may seem somewhat

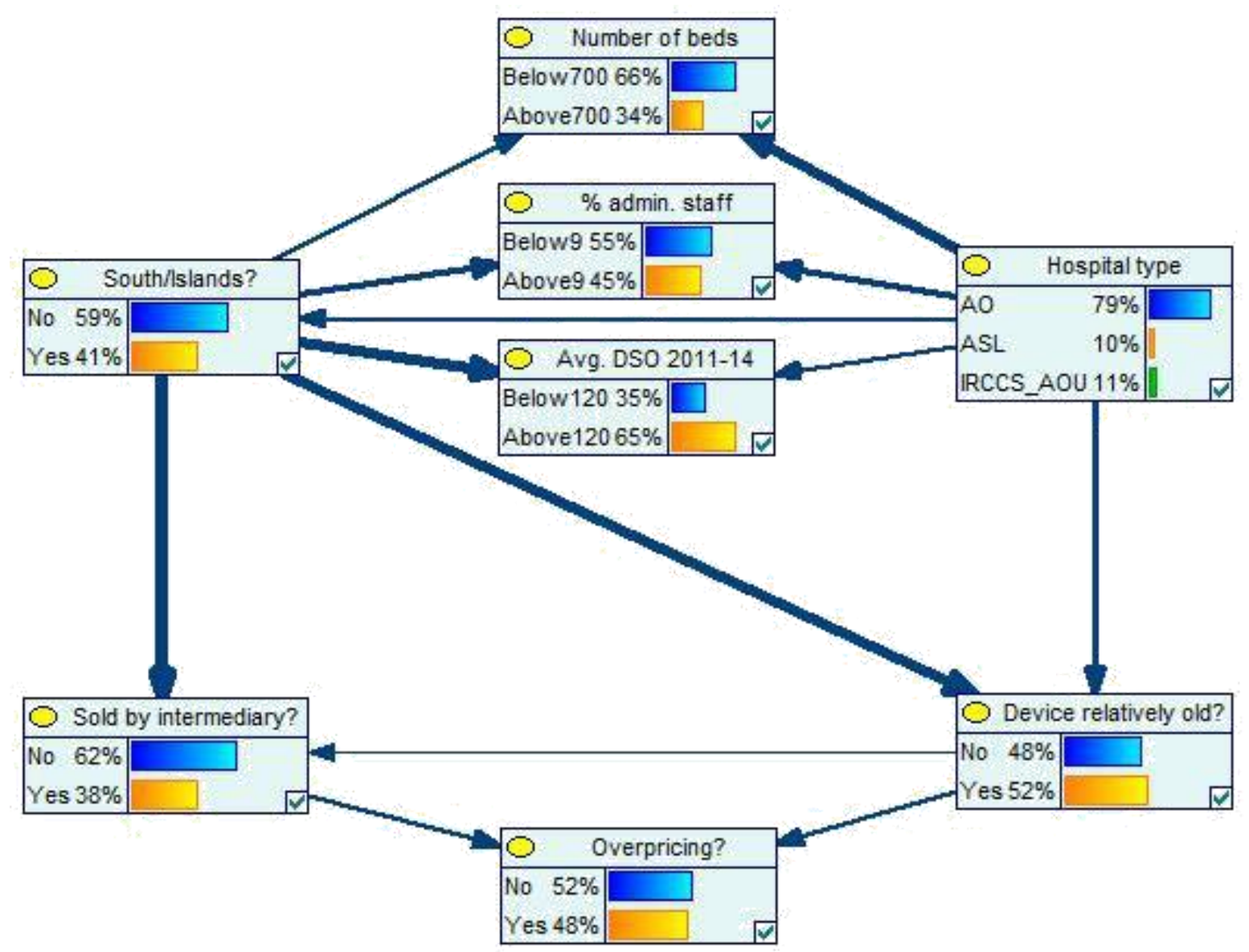

Figure 2: A Bayesian network learned from our data with a overpricing dummy at the CBIM ID level as target variable. The bars associated to each node show the marginal probability distribution of the variable, the thickness of the arcs shows the average strength of the correlation between variables.

arbitrary at first glance, because of two reasons: First, as already explained above, reducing the number of values that the variables can take means that less conditional probabilities have to be specified and therefore the maximum likelihood estimates are more robust, given a limited amount of data. Second, since our data is heavily clustered around some medical device procurers, a finer categorization of these hospital-level variables would imply that some values might almost completely made up by observations from one health firm. Since it is very likely that there are some unobserved hospital variables that are correlated with many of the observed variables, such a categorization might strongly bias our conditional probability estimates. Thus, we used two values with thresholds designed 
such that no value is made up by observations of just a few medical device. As a last note, because we have dropped all data rows with missing values, we have used only 4,623 observations to learn the network from the data. While the parameters of Figure 2 at the moment only represent the relative frequencies in the data, the average strength of the relationships, that is shown by the thickness of the arcs, already gives some interesting insights. As can be seen, there seem to be stronger correlations between the nodes that have been used as explanatory variables in the OLS analysis, than between those variables and the overpricing measure. Especially the node denoting whether a procurer is from the South or the Island regions of Italy has a very strong relationship with most other variables. This is in line with what has been said in section 2 about the regional variables that may possibly capture many effects that are also conditioning, or at least related to, the outcomes of nearly all of the other observed variables.

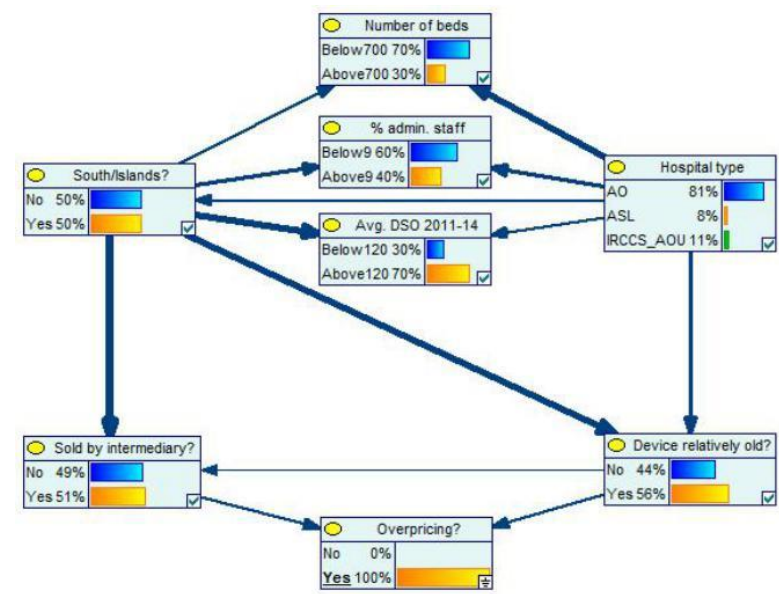

(a)

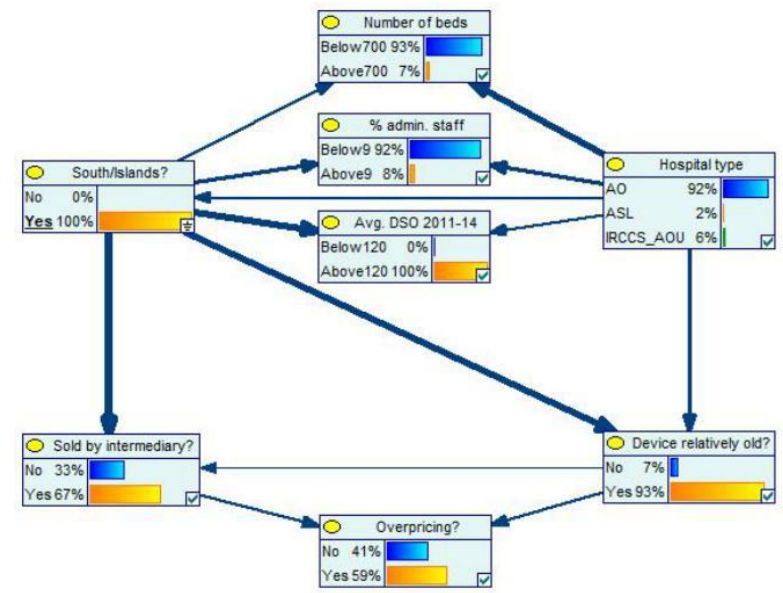

(c)

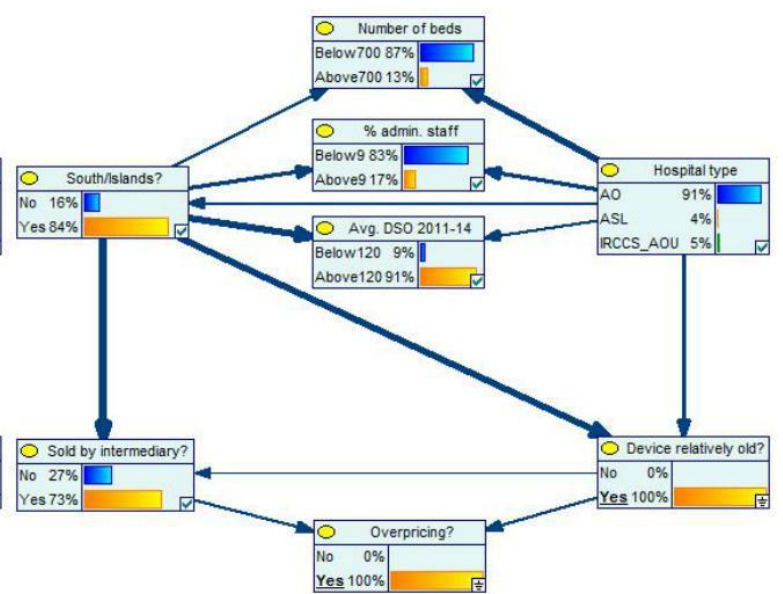

(b)

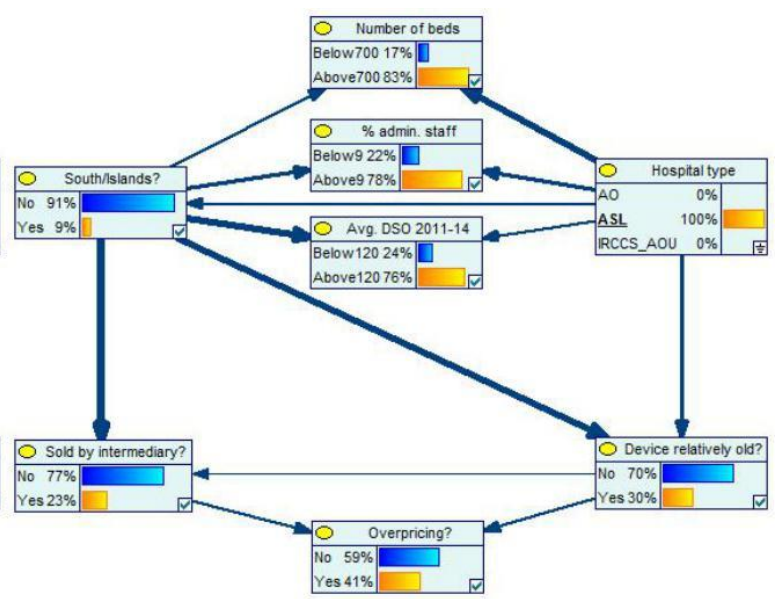

(d)

Figure 3: Examples of evidence propagation across our Bayesian network. 
One of the biggest advantages of using Bayesian networks is the fact that we can easily fix a variable at a certain level and see how this evidence propagates across the network, i.e. how it influences the marginal probability distribution of the other variables. Examples of such evidence propagation are shown in Figure 3, where in the first panel (a), we hold the overpricing dummy fixed at Yes to see what marginal probability distributions change the most. The resulting values do not show a very strong effect and one has to compare the marginal probabilities closely with those of Figure 2 to see the changes. As expected, if we know that a medical device has been overpriced, it is now more likely that the procurer is located in the South or on the Islands (50\% vs. $41 \%$ ). It also seems more likely that the device was sold by an intermediary, that the average DSO statistic is above 120 days, that the percentage of administrative staff is below $9 \%$ and surprisingly, it also seems to be more likely that the device in question is older than the average of the comparison group. While this might seem counterintuitive, especially when considering the robust negative effects of product age on price from the OLS estimation, the result becomes clearer when looking at panel (b) in Figure As can be seen, when we include additional evidence of a device being older than the average, the probability that the procurer is located in the South/Islands increases significantly to $84 \%$, as well as the strongly correlated DSO and intermediary variable ${ }^{20}$.

Thus, we can say that the total effect of the product age on the prices paid seems to be positive, given our data, because, as shown in panel (c), buying older products seems to be strongly correlated with the procurer being located in the South/Islands, having a higher DSO statistic and using an intermediary and therefore increase the prices paid ${ }^{2123}$. Furthermore, when keeping the South/Island dummy fixed while introducing evidence of overpricing (not shown in Figure 3), the results from the network seem to replicate those of the OLS estimations in section 4, where the partial effect of product age on prices is negative.

Finally, panel (d) shows how the marginal probability distributions of the variables change when we limit ourselves to ASL as device procurers. As can be seen, contrary to the OLS results, the probability of overpricing decreases. However, when taking a closer look at the other variables, we can again deduce that this might mostly stem from the higher probability of ASL to be located in the Center or North of Italy in our dataset. In conclusion, we think that in our case, an analysis based solely on learning a Bayesian network from data that is rather interdependent, clustered, and likely obscured by hidden variables, would not be sufficient to answer our economic research questions. However, including Bayesian networks seems to be a very useful addition to the analysis, especially since it

\footnotetext{
${ }^{20}$ The strong positive correlation between the South/Islands dummy and the product age is probably not representative for the underlying real world purchasing processes but is instead grounded in the way the data has been sampled. Since the BPA requesting parties, which are both from the South, make up a large part of the more recent data from the years 2013 and 2014, the products that they buy are naturally older than those of the public procurers that they are compared with using market research on procurement procedures that have already been carried out in the past.

${ }^{21}$ To test this result we construct a dummy variable that indicate when a device has been sold by an intermediary in the south/island area, this variable is always positive and highly consistent $(\mathrm{p}<0.05)$ for all model specification whit the value of the coefficient ranges from 16.72 to 34.28 percent point on PAM measure
} 
uncovered dependencies in the data that were not obvious from the results of the OLS estimation on our PAM measures. For example, it is rather interesting from an economic point of view that procurers from the South/Islands seem to be much more likely to purchase devices from independent intermediaries instead of buying directly from the manufacturers.

Table 4: Distribution of observations across regions and macroregions.

\begin{tabular}{lr|lr} 
Region & Obs. & Macroregion & Obs. \\
\hline \hline Lombardy & 2,586 & North-West & 2,828 \\
Piedmont & 168 & & \\
Liguria & 71 & & \\
Aosta Valley & 3 & & \\
\hline Emilia-Romagna & 319 & North-East & 439 \\
Veneto & 113 & & \\
Friuli-Venezia Giulia & 7 & & \\
\hline Marche & 419 & Center & 746 \\
Lazio & 127 & & \\
Umbria & 106 & & \\
Tuscany & 94 & & \\
\hline Apulia & 512 & South & 800 \\
Campania & 277 & & \\
Basilicata & 10 & & \\
Calabria & 1 & & \\
\hline Sicily & 2,395 & Islands & 2,499 \\
Sardinia & 104 & & \\
\hline \hline Total obs. & 7,312 & & 7,312
\end{tabular}

Table 5: Distribution of procurer types, average percentage of administrative personnel, average number of beds, and average DSO statistic per type.

\begin{tabular}{l|r||c|c|c} 
Type of procurer & Obs. & $\begin{array}{c}\text { Avg. percentage } \\
\text { of admin. staff }\end{array}$ & $\begin{array}{c}\text { Avg. number } \\
\text { of beds }\end{array}$ & $\begin{array}{c}\text { Avg. DSO } \\
\text { statistic }\end{array}$ \\
\hline AO & 5,106 & $7.04 \%$ & 648.98 & 238.01 \\
IRCCS/AOU/Policlinic & 1,376 & $10.86 \%$ & 1031.05 & 240.16 \\
ASL & 801 & $11.69 \%$ & 1182.40 & 219.70 \\
other (centralized) & 286 & & & 245.02 \\
other (not centralized) & 43 & & & 207.63 \\
\hline Total & 7,612 & $8.16 \%$ & 769.05 & 236.48
\end{tabular}


Table 6: Results of different specifications of an OLS estimation of several possible determinants of price dispersion on different percent-above-mean (PAM) price measures. (Macroregions)

\begin{tabular}{|c|c|c|c|c|c|}
\hline Variable & $\begin{array}{c}\text { (1) } \\
\text { obs2_pam }\end{array}$ & $\begin{array}{c}\text { (2) } \\
\text { obs3_pam }\end{array}$ & $\begin{array}{c}\text { (3) } \\
\text { rdm_pam }\end{array}$ & $\begin{array}{c}\text { (4) } \\
\text { rdm_pam }\end{array}$ & $\begin{array}{c}5) \\
\text { rdm10obs_pam }\end{array}$ \\
\hline ASL dummy & $\begin{array}{c}13.05^{\star * *} \\
(3.790)\end{array}$ & $\begin{array}{l}7.255^{\star *} \\
(3.551)\end{array}$ & $\begin{array}{c}12.63^{* * *} \\
(4.542)\end{array}$ & $\begin{array}{c}12.41^{* * *} \\
(4.291)\end{array}$ & $\begin{array}{c}19.61^{* * *} \\
(4.680)\end{array}$ \\
\hline IRCCS dummy & $\begin{array}{c}1.296 \\
(5.236)\end{array}$ & $\begin{array}{l}-1.504 \\
(4.869)\end{array}$ & $\begin{array}{l}0.0651 \\
(6.117)\end{array}$ & $\begin{array}{l}-0.443 \\
(6.773)\end{array}$ & $\begin{array}{l}-0.588 \\
(7.850)\end{array}$ \\
\hline South/Islands & $\begin{array}{c}8.779 \\
(5.540)\end{array}$ & $\begin{array}{l}15.04^{\star \star} \\
(6.531)\end{array}$ & $\begin{array}{c}31.57^{* * *} \\
(6.391)\end{array}$ & $\begin{array}{l}11.31^{*} \\
(6.238)\end{array}$ & $\begin{array}{l}38.00^{\star *} \\
(17.46)\end{array}$ \\
\hline BPA dummy & $\begin{array}{c}18.47^{\star \star \star *} \\
(5.790)\end{array}$ & & & $\begin{array}{l}12.73^{\star *} \\
(5.908)\end{array}$ & \\
\hline Avg. DSO 2011-14 & $\begin{array}{c}-0.0164 \\
(0.0122)\end{array}$ & $\begin{array}{c}0.0329 \\
(0.0316)\end{array}$ & $\begin{array}{c}-0.0407^{\star \star *} \\
(0.0106)\end{array}$ & $\begin{array}{c}-0.0301^{* *} \\
(0.0135)\end{array}$ & $\begin{array}{l}-0.00804 \\
(0.0697)\end{array}$ \\
\hline N. of beds & $\begin{array}{l}-0.00145 \\
(0.00333)\end{array}$ & $\begin{array}{l}-0.0111^{* *} \\
(0.00452)\end{array}$ & $\begin{array}{c}0.00127 \\
(0.00438)\end{array}$ & $\begin{array}{l}-0.00356 \\
(0.00399)\end{array}$ & $\begin{array}{l}-0.00113 \\
(0.00857)\end{array}$ \\
\hline Admin. staff (\%) & $\begin{array}{l}-1.559 \\
(1.027)\end{array}$ & $\begin{array}{l}-1.159 \\
(1.063)\end{array}$ & $\begin{array}{c}-2.322^{* \star} \\
(1.101)\end{array}$ & $\begin{array}{l}-0.977 \\
(1.242)\end{array}$ & $\begin{array}{l}-1.582 \\
(2.535)\end{array}$ \\
\hline Intermediary & $\begin{array}{l}4.487 \\
(7.609)\end{array}$ & $\begin{array}{l}-1.235 \\
(9.926)\end{array}$ & $\begin{array}{c}6.488 \\
(6.880)\end{array}$ & $\begin{array}{c}6.679 \\
(6.571)\end{array}$ & $\begin{array}{c}6.246 \\
(9.312)\end{array}$ \\
\hline Rel. product age & $\begin{array}{c}-0.255^{\star \star *} \\
(0.0535)\end{array}$ & $\begin{array}{c}-0.248^{\star *} \\
(0.102)\end{array}$ & $\begin{array}{c}-0.320^{* * *} \\
(0.0664)\end{array}$ & $\begin{array}{c}-0.308^{\star * *} \\
(0.0531)\end{array}$ & $\begin{array}{c}-0.432^{\star \star *} \\
(0.104)\end{array}$ \\
\hline Year 2010 & & $\begin{array}{c}-40.63^{\star \star *} \\
(5.463)\end{array}$ & & $\begin{array}{c}-13.96 \\
(14.71)\end{array}$ & \\
\hline Year 2011 & & $\begin{array}{c}5.534 \\
(6.599)\end{array}$ & & $\begin{array}{c}4.707 \\
(10.36)\end{array}$ & \\
\hline Year 2013 & & $\begin{array}{l}-7.444^{*} \\
(4.436)\end{array}$ & & $\begin{array}{l}-3.871 \\
(4.252)\end{array}$ & \\
\hline Year 2014 & & $\begin{array}{l}13.86^{\star \star} \\
(5.793)\end{array}$ & & $\begin{array}{c}9.158 \\
(6.821)\end{array}$ & \\
\hline Constant & $\begin{array}{c}5.191 \\
(8.003)\end{array}$ & $\begin{array}{l}8.951 \\
(8.488)\end{array}$ & $\begin{array}{c}11.41 \\
(7.844)\end{array}$ & $\begin{array}{c}2.809 \\
(9.226)\end{array}$ & $\begin{array}{l}-1.232 \\
(19.56)\end{array}$ \\
\hline $\begin{array}{l}\text { Observations } \\
\text { Prob. > F }\end{array}$ & $\begin{array}{l}4,623 \\
0.000\end{array}$ & $\begin{array}{l}2,367 \\
0.000\end{array}$ & $\begin{array}{l}4,623 \\
0.000\end{array}$ & $\begin{array}{l}4,623 \\
0.000\end{array}$ & $\begin{array}{l}3,502 \\
0.000\end{array}$ \\
\hline R-squared & 0.224 & 0.406 & 0.223 & 0.245 & 0.300 \\
\hline
\end{tabular}

Robust standard errors in parentheses, clustered at the procurer level.

$$
{ }^{* * *} p<0.01,{ }^{* *} p<0.05,{ }^{*} p<0.1
$$


Table 7: Results of different specifications of an OLS estimation of several possible determinants of price dispersion on different percent-above-mean (PAM) price measures (Regional Organization Models).

\begin{tabular}{|c|c|c|c|c|}
\hline VARIABLES & $\begin{array}{c}\text { (6) } \\
\text { obs2_pam }\end{array}$ & $\begin{array}{c}\text { (7) } \\
\text { obs3_pam }\end{array}$ & $\begin{array}{c}\text { (8) } \\
\text { obs3_pam }\end{array}$ & $\begin{array}{c}(9) \\
\text { rdm_pam }\end{array}$ \\
\hline ASL dummy & $\begin{array}{l}9.454^{*} \\
(5.091)\end{array}$ & $\begin{array}{c}9.266 \\
(5.748)\end{array}$ & $\begin{array}{c}6.895 \\
(4.677)\end{array}$ & $\begin{array}{c}7.614 \\
(6.680)\end{array}$ \\
\hline IRCCS dummy & $\begin{array}{l}7.542^{* *} \\
(3.684)\end{array}$ & $\begin{array}{c}3.287 \\
(5.241)\end{array}$ & $\begin{array}{c}1.668 \\
(5.269)\end{array}$ & $\begin{array}{c}4.491 \\
(5.622)\end{array}$ \\
\hline Integrated & $\begin{array}{c}-28.68^{* * *} \\
(5.924)\end{array}$ & $\begin{array}{c}-30.40^{* * *} \\
(10.18)\end{array}$ & $\begin{array}{l}-20.83^{* *} \\
(8.305)\end{array}$ & $\begin{array}{c}-18.88^{* * *} \\
(6.110)\end{array}$ \\
\hline Semi-integrated & $\begin{array}{c}-29.50^{* * *} \\
(5.321)\end{array}$ & $\begin{array}{c}-34.24^{\star * \star} \\
(11.18)\end{array}$ & $\begin{array}{c}-20.02^{* *} \\
(9.314)\end{array}$ & $\begin{array}{c}-15.04^{\star \star} \\
(6.635)\end{array}$ \\
\hline Separated & $\begin{array}{c}-32.71^{* * *} \\
(8.392)\end{array}$ & $\begin{array}{l}-34.02^{*} \\
(17.50)\end{array}$ & $\begin{array}{l}-22.15 \\
(13.76)\end{array}$ & $\begin{array}{c}-21.93^{\star *} \\
(9.848)\end{array}$ \\
\hline Avg. DSO 2011-14 & $\begin{array}{c}-0.0355^{\star \star *} \\
(0.0111)\end{array}$ & $\begin{array}{c}0.0460 \\
(0.0518)\end{array}$ & $\begin{array}{c}0.0353 \\
(0.0408)\end{array}$ & $\begin{array}{c}-0.0416^{\star * *} \\
(0.0109)\end{array}$ \\
\hline N. of beds & $\begin{array}{l}0.000121 \\
(0.00301)\end{array}$ & $\begin{array}{c}-0.00534 \\
(0.00462)\end{array}$ & $\begin{array}{l}-0.0105^{\star *} \\
(0.00484)\end{array}$ & $\begin{array}{c}-0.00622 \\
(0.00419)\end{array}$ \\
\hline Admin. staff (\%) & $\begin{array}{l}-0.951 \\
(1.041)\end{array}$ & $\begin{array}{l}-1.249 \\
(1.169)\end{array}$ & $\begin{array}{l}-0.684 \\
(1.098)\end{array}$ & $\begin{array}{l}-0.290 \\
(1.167)\end{array}$ \\
\hline Intermediary & $\begin{array}{c}5.169 \\
(7.675)\end{array}$ & $\begin{array}{c}-2.622 \\
(10.92)\end{array}$ & $\begin{array}{l}-1.862 \\
(10.12)\end{array}$ & $\begin{array}{c}7.466 \\
(6.559)\end{array}$ \\
\hline Rel. product age & $\begin{array}{c}-0.195^{\star \star \star} \\
(0.0456)\end{array}$ & $\begin{array}{c}-0.320^{\star \star \star} \\
(0.0823)\end{array}$ & $\begin{array}{c}-0.246^{\star *} \\
(0.102)\end{array}$ & $\begin{array}{c}-0.255^{\star \star *} \\
(0.0611)\end{array}$ \\
\hline Year 2010 & & & $\begin{array}{c}-36.33^{* * *} \\
(8.531)\end{array}$ & $\begin{array}{l}-8.969 \\
(13.34)\end{array}$ \\
\hline Year 2011 & & & $\begin{array}{l}6.018 \\
(6.514)\end{array}$ & $\begin{array}{c}4.798 \\
(11.28)\end{array}$ \\
\hline Year 2013 & & & $\begin{array}{l}-6.499 \\
(4.309)\end{array}$ & $\begin{array}{c}-3.023 \\
(4.217)\end{array}$ \\
\hline Year 2014 & & & $\begin{array}{l}10.05 \\
(6.879)\end{array}$ & $\begin{array}{l}14.87^{* *} \\
(6.026)\end{array}$ \\
\hline Constant & $\begin{array}{c}33.22^{* * *} \\
(6.899)\end{array}$ & $\begin{array}{l}33.68^{* *} \\
(16.28)\end{array}$ & $\begin{array}{l}25.25^{\star} \\
(14.35)\end{array}$ & $\begin{array}{l}20.94^{* *} \\
(8.571)\end{array}$ \\
\hline Observations & 4,623 & 2,367 & 2,367 & 4,623 \\
\hline R-squared & 0.228 & 0.387 & 0.407 & 0.233 \\
\hline
\end{tabular}

Robust standard errors in parentheses

${ }^{* * *} p<0.01,{ }^{* *} p<0.05,{ }^{*} p<0.1$ 
Table 8: Different OLS regression specifications including a dummy for centralized procurement

\begin{tabular}{|c|c|c|c|c|c|c|}
\hline Variable & $\begin{array}{c}\text { (10) } \\
\text { obs2_pam }\end{array}$ & $\begin{array}{c}\text { (11) } \\
\text { obs2_pam }\end{array}$ & $\begin{array}{c}\text { (12) } \\
\text { obs3_pam }\end{array}$ & $\begin{array}{c}(13) \\
\text { mrobs2 } \\
\text { pam }\end{array}$ & $\begin{array}{c}(14) \\
\text { mrobs2 } \\
\text { rdm_pam }\end{array}$ & $\begin{array}{c}(15) \\
\text { rdm_pam }\end{array}$ \\
\hline ASL & $\begin{array}{c}3.081 \\
(2.858)\end{array}$ & $\begin{array}{c}5.661 \\
(3.521)\end{array}$ & $\begin{array}{c}0.968 \\
(4.138)\end{array}$ & $\begin{array}{c}3.997 \\
(2.783)\end{array}$ & $\begin{array}{c}3.580 \\
(4.398)\end{array}$ & $\begin{array}{c}6.100 \\
(4.273)\end{array}$ \\
\hline IRCCS & $\begin{array}{l}-1.242 \\
(5.050)\end{array}$ & $\begin{array}{l}-2.157 \\
(4.375)\end{array}$ & $\begin{array}{l}-8.925^{*} \\
(4.829)\end{array}$ & $\begin{array}{l}-4.606^{*} \\
(2.334)\end{array}$ & $\begin{array}{l}-4.585 \\
(4.495)\end{array}$ & $\begin{array}{l}-4.835 \\
(4.634)\end{array}$ \\
\hline Central. & $\begin{array}{c}-15.46^{\star *} \\
(6.021)\end{array}$ & $\begin{array}{c}-26.48^{\star \star \star} \\
(5.816)\end{array}$ & $\begin{array}{c}-29.98^{\star \star *} \\
(4.151)\end{array}$ & $\begin{array}{c}-6.886^{\star *} \\
(2.616)\end{array}$ & $\begin{array}{c}-7.416^{* *} \\
(3.384)\end{array}$ & $\begin{array}{c}-30.90^{\star \star \star} \\
(6.333)\end{array}$ \\
\hline Sout & $\begin{array}{c}12.46^{* * *} \\
(3.187)\end{array}$ & $\begin{array}{c}27.08^{\star \star \star} \\
(4.786)\end{array}$ & $\begin{array}{c}23.67^{* * *} \\
(6.226)\end{array}$ & $\begin{array}{c}4.411 \\
(2.911)\end{array}$ & $\begin{array}{c}4.796 \\
(4.143)\end{array}$ & $\begin{array}{c}30.43^{* * *} \\
(5.549)\end{array}$ \\
\hline DSO & & $\begin{array}{c}-0.0177 \\
(0.0146)\end{array}$ & $\begin{array}{l}0.0560^{*} \\
(0.0300)\end{array}$ & $\begin{array}{c}0.0117 \\
(0.0178)\end{array}$ & $\begin{array}{l}-0.00204 \\
(0.0310)\end{array}$ & $\begin{array}{c}-0.0181 \\
(0.0167)\end{array}$ \\
\hline Rel. age & & $\begin{array}{c}-0.188^{* * *} \\
(0.0332)\end{array}$ & $\begin{array}{c}-0.303^{\star * *} \\
(0.0852)\end{array}$ & $\begin{array}{c}-0.278^{\star * *} \\
(0.0378)\end{array}$ & $\begin{array}{c}-0.219^{\star \star \star} \\
(0.0570)\end{array}$ & $\begin{array}{c}-0.269^{\star \star \star} \\
(0.0510)\end{array}$ \\
\hline Co & $\begin{array}{l}-4.544^{*} \\
(2.665)\end{array}$ & $\begin{array}{l}-6.464^{*} \\
(3.868)\end{array}$ & $\begin{array}{c}-15.74^{\star *} \\
(6.227)\end{array}$ & $\begin{array}{l}-3.160 \\
(2.760)\end{array}$ & $\begin{array}{l}-0.566 \\
(3.586)\end{array}$ & $\begin{array}{l}-7.719^{*} \\
(4.309)\end{array}$ \\
\hline $\begin{array}{l}\text { Obs. } \\
\text { Prob. }\end{array}$ & $\begin{array}{l}7,273 \\
0.000\end{array}$ & $\begin{array}{l}5,652 \\
0.000\end{array}$ & $\begin{array}{l}2,908 \\
0.000\end{array}$ & $\begin{array}{l}2,156 \\
0.000\end{array}$ & $\begin{array}{l}3,165 \\
0.000\end{array}$ & $\begin{array}{l}5,652 \\
0.000\end{array}$ \\
\hline R-squared & 0.086 & 0.147 & 0.255 & 0.141 & 0.079 & 0.147 \\
\hline
\end{tabular}

Robust standard errors in parentheses, clustered at the procurer level. ${ }^{* * *} p<0.01,{ }^{* *} p<0.05,{ }^{*} p<0.1$ 


\section{Conclusions}

We have carried out a double statistical analysis to identify the observable factors that influence price dispersion in the Italian medical device industry. Then we have tried to analyse to what extent price dispersion depends on price discrimination. In a first step, we have found that such a dispersion exists and is substantial, with average price coefficients of variation ranging from $12 \%$ to $22 \%$ for identical medical devices. Using multiple OLS model specifications, we have then identified four significant variables that seem to be affecting the final price that public medical device procurers have to pay. It seems that public procurers from the South and the Islands pay significantly higher prices than those located in the North or Center of Italy. Even when we try to control for different type of regional organization models we still find that models mainly adopted in southern regions lead to higher prices with respect to models adopted in northern Italy. While this finding can be consistent with price discrimination, a possible cause of geographical price dispersion arises from the Bayesian Network Analysis. Exploring the propagation mechanism inherent to these networks, this analysis has uncovered other dependencies that did not result from the econometric investigation. We have found that the probability of a public procurer to purchase from an independent medical device retailer is much higher for buyers located in the macroregions South or Islands than for those located in Northern or Central Italy. Furthermore the anlysis shows that retailers charge higher prices for "older" medical devices therefore geographical price differences could be motivated by double marginalization, especially if retailers located in the South are expected to enjoy market power at a local level. Some anecdotal evidence provided by CBIM seems to support this view, as far as local retailers seem to exert a lot of influence in Southern regions where manufacturers are generally not present with their own distribution network. One could then suspect that local retailers may be able to exert also some monopsony power toward producers that want to sell their product in the South of Italy. However a more detailed analysis of the market for medical devices in Southern Regions would be necessary to confirm the suggestions provided by anecdotal evidence.

In the case of single hospital purchasing, we find that ASL seem to incur higher costs than $\mathrm{AO}$ in the acquisition of medical devices ${ }^{2224}$. One possible reason for this difference may be that single AO purchase larger quantities of medical devices than ASL and therefore can get discounts. When including observations from centralized purchasing agencies, the results indicate that these bodies pay significantly lower prices than single purchasers. Therefore second degree price discrimination could be invoked to explain significant price differences between $\mathrm{AO}, \mathrm{ASL}$ and Central Purchasing Agencies. Finally, the variable approximating the product age has a very robust negative impact on prices, implying that, as expected, medical devices are more expensive when they represent a recent

\footnotetext{
${ }^{22}$ Of course the distinction between AO and ASL as purchasers is significant only for those Regions where this distinction holds (like for example Lombardy, Sicily, Lazio). In other Regions purchase is centralized by ASL and of course no difference would arise.
} 
innovation and become less expensive over time. In this last case higher prices may be due to the supplier cost for innovation and do not necessarily imply price dis-crimination. Late payments are also frequently invoked by sellers as a cause of significant price differences. However the results we find are not sufficiently robust to confirm that higher prices actually depend on late payments and that price discrimination may ensue from the late payments variable. However, there are some limitations of this analysis that will need further research activities. First, the very important quantity variable has too many missing values to be included into our analysis. Especially the effect of the centralization variable could in large part be associated to higher average quantities. It would then be interesting to see whether it is purchase centralization per se, or whether it is the larger contract scale that leads to lower final prices.

As far as the variable constructions are concerned, there might be some further refinements that could be done. As already mentioned, it would be interesting to see if a construction of the DSO variable, that includes a two-year average of the statistic before the purchase was made, would yield more significant results. Also the centralization variable could be refined and separate variables for centralized regional procurers and purchasing unions could be created. This can, however, only be done if additional observations from centralized procurers were included into the data. Also a better proxy for physician preferences could be constructed and possibly yield significant results.

Finally, if the Bayesian network analysis were expanded, it would be important to deal with the clusters in our data. Especially the high prevalence of certain hospitals might lead to an overestimation of the dependencies between certain variables. As a final suggestion, it might be interesting to include more prior beliefs into the analysis, such as, for example, the results of the OLS estimations. 


\section{References}

Assobiomedica, 2010. La posizione associativa in tema di prezzi dei dispositivi medici: Attenzione ai confronti impropri.

http://www.assobiomedica.it/static/upload/pp_/pp_ _prezzidispositivi-03.pdf.

Bonaccorsi, A., Lyon, T. P., Pammolli, F., Turchetti, G., November 2000. Auctions vs. bargaining: An empirical analysis of medical device procurement. LEM Working Paper Series.

Boscolo, P. R., Tarricone, R., 2013. La rilevanza economica e sociale del mercato dei dispositivi medici. caratteristiche distintive del prodotto, delle imprese produttrici e delle relazioni con il settore pubblico. Aidea 2013 Conference Papers.

Burns, L. R., Lee, J. A., 2008. Hospital purchasing alliances: utilization, services, and performance. Health Care Management Review 33 (3), 203-215.

Centro Studi Assobiomedica, 2012a. I tempi medi di pagamento delle strutture sanitarie pubbliche. Studi n.24.

Centro Studi Assobiomedica, 2012b. Produzione, ricerca e innovazione nel settore dei dispositivi medici in Italia. Rapporto.

Centro Studi Assobiomedica, 2013. I tempi medi di pagamento delle strutture sanitarie pubbliche. Studi n.25.

Centro Studi Assobiomedica, 2014. Average payment times of public and private health-care organisations. Studies n.28.

Centro Studi Assobiomedica, 2015a. I tempi medi di pagamento delle strutture sanitarie pubbliche e private. Studi n.31.

Centro Studi Assobiomedica, 2015b. Le politiche pubbliche d'acquisto di dispositivi medici. Studi n.30.

Centro Studi Assobiomedica, 2016. Le politiche pubbliche d'acquisto di dispositivi medici, secondo aggiornameto. Studi n.33.

Dimitri, N., Dini, F., Piga, G., 2006. When should procurement be centralized. Handbook of procurement, 47-81.

Di Novi, Rizzi, Zanette, 2017. Scale effects and expected savings from consolidation policies of Italian local healthcare authorities. Applied Health Economics and Health Policy. 
Eucomed, January 2014a. The European medical technology industry in figures http://www.eucomed.be/uploads/Modules/Publications/ 20141003medtech-brochure-digital-1.pdf.

Eucomed, October 2014b. Key principles of smart procurement for medical devices http://www.medtecheurope.org/uploads/Modules/Publications/20141020_ eucomed-key-principles-of-smart-procurement-for-medical-devices-final. pdf.

European Council Directive 93/42/EEC of June 14, 1993.

Ferré, F., de Belvis, A. G., Valerio, L., Longhi, S., Lazzari, A., Fattore, G., Ricciardi, W., Maresso, A., 2014. Italy: Health system review. Health Systems in Transition 16 (4).

Grennan, M., 2013. Price discrimination and bargaining: Empirical evidence from medical devices. American Economic Review 103 (1), 145-77.

Hahn, R. W., Klovers, K. B., Singer, H. J., 2008. The need for greater price transparency in the medical device industry: an economic analysis. Health Affairs 27 (6), 1554-1559.

Italian Legislative Decree n. 46 of February 24, 1997. Attuazione della direttiva 93/42/CEE concernente i dispositivi medici. Gazzetta Ufficiale della Repubblica Italiana n. 54 del 6 marzo 1997.

Italian Legislative Decree n.163 of April 12, 2006. Codice dei contratti pubblici relativi a lavori, servizi e forniture in attuazione delle direttive 2004/17/CE e 2004/18/CE. Gazzetta Ufficiale della Repubblica Italiana n. 100 del 2 maggio 2006.

Kjerstad, E., 2005. Auctions vs negotiations: a study of price differentials. Health economics 14 (12), 1239-1251.

Lerner, J. C., Fox, D. M., Nelson, T., Reiss, J. B., 2008. The consequence of secret prices: the politics of physician preference items. Health Affairs 27 (6), 1560-1565.

Ministero della Salute, 2014. Rapporto sulla spesa rilevata dalle strutture sanitarie pubbliche del SSN per l'acquisto di dispositivi medici - anno 2013. http://www.salute.gov.it/imgs/C_17_pubblicazioni_2259_allegato.pdf.

Nielsen, T. D., Jensen, F. V., 2009. Bayesian networks and decision graphs. Springer Science \& Business Media.

Pammolli, F., Riccaboni, M., Oglialoro, C., Magazzini, L., Baio, G., Salerno, N., 2005. Medical devices competitiveness and impact on public health expenditure. Entreprise Directorate-General, European Commission. 
Pauly, M. V., Burns, L. R., 2008. Price transparency for medical devices. Health Affairs 27 (6), 1544-1553.

Sorenson, C., Kanavos, P., 2011. Medical technology procurement in europe: A crosscountry comparison of current practice and policy. Health Policy 100 (1), 43-50.

Stigler, G., 1987. Theory of price. Macmillan New York.

Stole, L. A., 2007. Price discrimination and competition. Handbook of industrial organi-zation 3, 2221-2299.

Tirole, J., 1988. The theory of industrial organization. MIT press.

Varian, H. R., 1989. Price discrimination. Handbook of industrial organization 1, $597-654$.

Vellez, M., 2011. Auctions versus negotiations: Evidence from public procurement in the Italian healthcare sector. CEIS Working Papers.

Vellez, M., 2012. Determinants of price discrimination in the acquisition of medical devices. CEIS Working Papers.

Wooldridge, J., 2009. Introductory econometrics: A modern approach, 4th Edition. Cengage Learning. 